January 2018

\title{
Analysis Of Pressure Distribution Along Pipeline Blockage Based On The Cfd Simulation
}

Lu Yang

How does access to this work benefit you? Let us know!

Follow this and additional works at: https://commons.und.edu/theses

\section{Recommended Citation}

Yang, Lu, "Analysis Of Pressure Distribution Along Pipeline Blockage Based On The Cfd Simulation" (2018). Theses and Dissertations. 2439.

https://commons.und.edu/theses/2439

This Thesis is brought to you for free and open access by the Theses, Dissertations, and Senior Projects at UND Scholarly Commons. It has been accepted for inclusion in Theses and Dissertations by an authorized administrator of UND Scholarly Commons. For more information, please contact und.commons@library.und.edu. 


\title{
ANALYSIS OF PRESSURE DISTRIBUTION ALONG PIPELINE BLOCKAGE BASED ON THE CFD SIMULATION
}

\author{
by \\ Lu Yang \\ Master of Science, Northeast Petroleum University, China, 2017
}

\author{
A Thesis \\ Submitted to the Graduate Faculty \\ of the \\ University of North Dakota \\ In partial fulfillment of the requirements
}

for the degree of

Master of Science

In Petroleum Engineering

Grand Forks, North Dakota

December

2018 
This thesis, submitted by Lu Yang in partial fulfillment of the requirements for the Degree of Master of Science in Petroleum Engineering from the University of North Dakota, has been read by the Faculty Advisory Committee under whom the work has been done and is hereby approved.

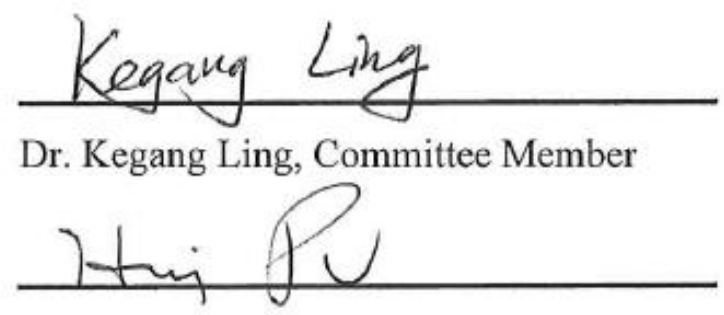

Dr. Hui Pu, Committee Member

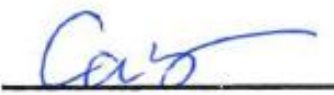

Dr. Caixia Yang, Committee Member

This thesis is being submitted by the appointed advisory committee as having met all of the requirements of the School of Graduate Students at the University of North Dakota and it hereby approved.

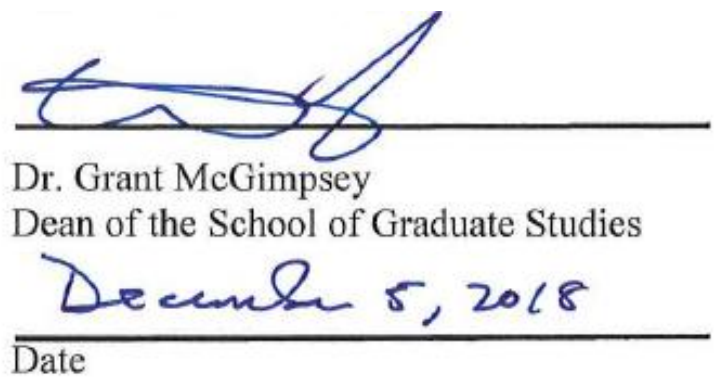




\section{PERMISSION}

\section{Title ANALYSIS OF PRESSURE DISTRIBUTION ALONG PIPELINE BLOCKAGE BASED ON THE CFD SIMULATION}

Department Petroleum Engineering

Degree Master of Science

In presenting this thesis in partial fulfillment of the requirements for a graduate degree from the University of North Dakota, I agree that the library of this University shall make it freely available for inspection. I further agree that permission for extensive copying for scholarly purposes may be granted by the professor who supervised my thesis work or, in his absence, by the Chairperson of the department or the dean of the School of Graduate Studies. It is understood that any copying or publication or other use of this thesis or part thereof for financial gain shall not be allowed without my written permission. It is also understood that due recognition shall be given to me and to the University of North Dakota in any scholarly use which may be made of any material in my thesis.

Lu Yang

Dec. 27,2018 


\section{TABLE OF CONTENTS}

LIST OF FIGURES ...........................................................vi

LIST OF TABLES..........................................................

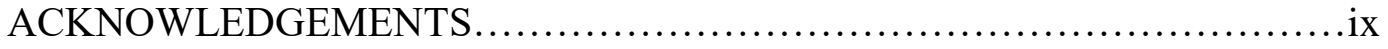

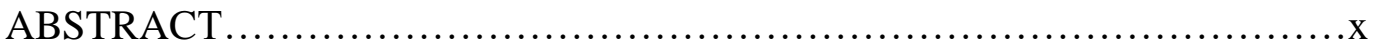

CHAPTER

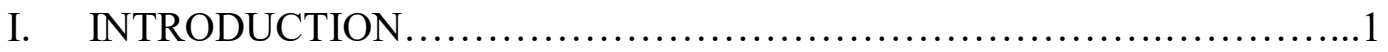

1.1 General Background..............................................

1.2 Main Causes of Pipeline Blockage .................................

1.3 Literature Review on Blockage Detection............................. 3

1.4 Objectives and Organization of the Thesis...........................11

II. CFD SIMULATION METHOD OF PIPELINE BLOCKAGE ...............13

2.1 Governing Equations.......................................... 13

2.2 Computational Domain and Mesh................................15

2.3 Solution Method and Boundary Conditions........................17

2.4 Simulation Result and Discussion.............................17

III. EFFECTS OF BLOCKAGE CHARACTERIZATION ON PRESSURE DISTRIBUTION AND DIMENSIONLESS ANALYSIS .........................25

3.1 Effects of the Blockage Characterizations on Pressure Distribution....25

3.2 OAT (Orthogonal Array Testing) Technique.........................30

3.3 Dimensionless Analysis for Blockage Prediction.....................31 
IV. BLOCKAGE PREDICTION MODEL VALIDATION ...................... 35

4.1 Laboratory Experiment Set-up.................................35

4.2 Experiment Investigation.................................. 39

4.3 Experiment Results and Discussion............................42

V. CONCLUSIONS AND FUTURE WORKS ...........................45

5.1 Conclusions...............................................45

5.2 Future Works..................................................46

NOMENCLATURE...................................................48

REFERENCES ......................................................... 50 


\section{LIST OF FIGURES}

Figure

2.1 3D computational domain: (a) pipeline without blockage; (b) pipeline with blockage. 15

2.2 3D computational meshing. .16

2.3 CFD simulation of the effect of the pressure drop on pipeline flow rate under different

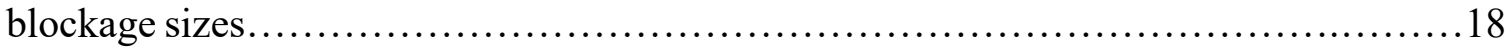

2.4 Pressure distribution through the pipe centerline without blockage.................19

2.5 Pressure gradient distribution through the pipe centerline without blockage..........19

2.6 Pressure distribution through the pipe centerline with blockage $\ldots \ldots \ldots \ldots \ldots \ldots \ldots \ldots .20$

2.7 Pressure gradient distribution through the pipe centerline with blockage.............20

2.8 Pressure distribution along lines below the blockage boundary $\ldots \ldots \ldots \ldots \ldots \ldots \ldots \ldots . .21$

2.9 Zoom-in view of pressure gradient contour of blockage inlet part.................22

2.10 Pressure gradient distribution along lines below the blockage boundary...........23

2.11 Contours of turbulent kinetic energy around the blockage.......................24

3.1 Pressure distribution through the pipeline with blockage in various locations........26

3.2 Pressure gradient distribution through blockage in various locations................26

3.3 Pressure distribution through the pipeline with blockage in various inner diameter...27

3.4 Zoom in pressure gradient distribution through blockage in various inner diameters.28

3.5 Pressure distribution through the pipeline with blockage in various lengths..........29

3.6 Pressure gradient distribution through blockage in various lengths.................29 
3.7 Dimensionless pressure drop through pipeline under various parameters

3.8 Blockage estimation figure based on dimensionless analysis. .33

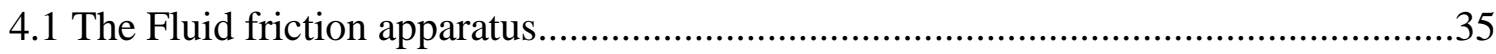

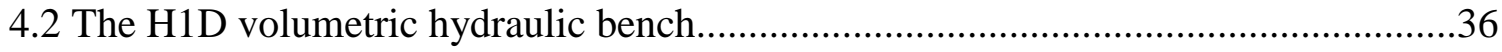

4.3 Experimental setup for pipeline blockage investigation........................ 37

4.4 The Instruments used for the blockage experiments.......................... 37

4.5 The Data logging system used for the blockage experiments.....................38

4.6 LabVIEW Software used for pipeline blockage experiment........................39 


\section{LIST OF TABLES}

Table

1.1 Merits and demerits of different detection methods ............................ 10

1.2 Applicability of different methods.........................................11

2.1 CFD computational domain parameters...................................

3.1 Factors and levels for the orthogonal test.................................. 30

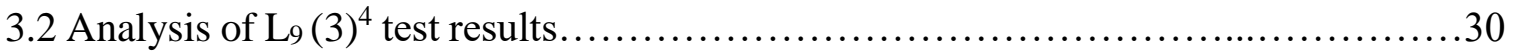

4.1 Experiment parameters for standard cases.................................40

4.2 Experiment parameters for single blockage at different locations.................40

4.3 Experiment parameters for single blockage with different diameters...............41

4.4 Experiment parameters for single blockage with different lengths.................41

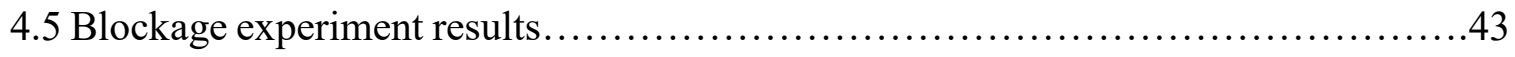

4.6 Blockage prediction model validation......................................44 


\section{ACKNOWLEDGEMENTS}

I would like to thank my supervisor, Dr. Kegang Ling, for his guidance, encouragement and advice he provided throughout my time as his student. I have been honored to have a supervisor who patient so much, and who responded to my questions and queries so promptly.

I am grateful to my committee members Dr. Hui Pu and Dr. Caixia Yang for their advice and support. I would also like to recognize the faculty and the staff of the Petroleum Engineering Department for their encouragement during my master's study at UND.

I must express my deep gratitude to my family, for their continued support and encouragement. Finally, I would like to thank my new friends in UND for their love and support. 


\begin{abstract}
Pipeline blockage, which results from solid and hydrocarbon deposition caused by changes in pressure, temperature, or composition, is a critical issue in oil \& gas production and transportation systems. Sometimes blockage, which extends several miles in the longdistance pipeline, can be assumed as a new pipe with a smaller diameter. Therefore, it is imperative to detect the location and size of blockage in pipelines more accurately and efficiently to reduce the number of pipeline accidents.

This paper explores the distribution of pressure and pressure gradient through the pipeline without/with single blockage under different operating conditions. 3-dimensional (3D) computational fluid dynamic (CFD) simulations under steady state are carried out to examine the effects of blockage location, blockage diameter and blockage length. The orthogonal array testing technique is applied to study the extent to which factor affects the pressure drop most.

The dimensionless parameters like dimensionless blockage location, dimensionless blockage diameter, dimensionless blockage length and dimensionless pressure drop, are introduced to evaluate the relationship among the pressure drop and blockage characterizations. Three fitting formulas of dimensionless parameters distribution are proposed and could be used to locate the pipeline blockage and estimate its diameter and length as well.
\end{abstract}


Finally, laboratory experiments were run to validate the blockage prediction model. The fluid frictional apparatus is modified by replacing part of the pipe with a section of small diameter pipe to simulate the actual partial blockade pipeline. The obtained deviations of pressure drop between the lab experiment result and the prediction model is limited to under $30 \%$. Therefore, the deviation should be taken into account while assessing the blockage through the pipeline based on the blockage prediction model, which also allow the operator to assess partial blockage efficiently and economically. 


\section{CHAPTER I \\ INTRODUCTION}

\subsection{General Background}

The unintentional deposition of fluid in the process of pipeline transportation is characterized as blockage. Pipeline blockage, may result from, bad operating conditions, any reason due to sudden changes of pressure, temperature, composition, corrosion action, or lack of maintenance. In most cases, the deleterious effects associated with the occurrence of blockages may present serious problems. Especially as the boom of the Bakken shale reservoirs production, more new pipelines are constructed to meet the transportation requirement of ever-increasing crude oil and natural gas, refined products, carbon dioxide, and produced water. At the same time, the original pipe networks are aging. New pipelines as well as the original pipe networks will inevitably experience more blockage problems during operation, which also increases the need for more intelligent blockage detection methods to better evaluate and locate blockage. It is therefore no surprise that pipeline blockages must be quickly detected, estimated, located and repaired.

\subsection{Main Causes of Pipeline Blockage}

Pipeline blockage can be caused by a number of different factors. Some examples include the formation such as asphaltene, wax, or gas hydrate because of operating conditions like high pressure or low temperature. Also blockage can form by some inorganic causes like sand deposition or scaling. Due to the incompatibility of chemical or well streams. Other common factors that generate blockage are mechanical causes like 
stalled pigs, collapsed pipe or failed valves. Due to its variety formation conditions, pipeline blockage can and does occur anywhere from the sand surface to the export pipe networks (Bukkaraju, 2016). From the field operation and flow assurance engineering experience, some of the following events suggest the partial pipeline blockage:

- Increased pressure drop along the flow path from the inlet to the outlet.

- Reduced flow rate suddenly or complete loss of the fluid.

- Increased difference in temperature along the pipeline from original value because of the cooling or heating effect.

- Presence of small hydrate, wax presence, or sand in the routine pigging returns. Existence of a pipeline blockage poses serious risks. Pipeline blockage can not only reduce the operation efficiency of pipe network, but also may cause a safety problem if the blockage has not been detected accurately and removed quickly. The accident can reduce the profit of project or delay the project significantly (Rui et al., 2017a, 2017b, and 2017c). It is believed that accurate location of pipeline blockage can reduce the risks by appropriate detection methods. While before any detection method is taken, it is necessary to make appropriate assessments of the nature and severity of the pipeline blockage. Blockage characterization is assessed in several aspects including fluid characterization, operating condition and pipe system assessment.

(1) Fluid characterization

Understanding the produced fluid characteristics and the propensity to fluid mechanisms, are of critical importance to estimate the potential risk of generating blockage in pipeline system. Pipeline blockage varies due to the difference between the fluids being transported. The major threats for flow assurance are proposed by Sampath K. (2016) that 
include hydrate, wax and asphaltenes. Hydrate blockage, always found in gas pipelines, has not only high dependency on low temperature or high pressure, but also on water presence. Wax blockage in crude oil pipeline is formed when the fluid flow cools down, especially wax crystals are usually transported and deposited on the pipe wall during winter. Asphaltenes presence in reservoir fluid are usually dependent on system pressure changes, with the risk of plugging the reservoir perforations. Fluid compositional analysis (e.g. water-cut, gravity, GOR), fluid properties analysis (e.g. viscosity, dew point), hydrate/ wax/ asphaltene characterization, fluid assurance state analysis (e.g. steady state or transient state), and fluid mechanics can be of benefit for blockage characterization.

(2) Operating condition

Tracking the pipeline system operating parameters helps greatly in assessing the nature of the blockage. Simulation and fluid modeling also help estimate the fluid characteristics. Operating pressure, temperature and fluid conditions along the pipeline system need to be known in order to effectively estimate with higher accuracy the nature of the blockage. High pressure and low temperature-driven pipeline blockages such as hydrate/ wax/ asphaltenes may occur simultaneously at some certain conditions, but can require different methods to detect and estimate. Besides, under some operating conditions not only the partial blockage is present, but some multiphase blockages or multiple blockages will be present especially for the pipeline over long distance. Flow assurance and operation experience have shown that in many field cases once the operating conditions are misunderstood, and wrong methods for blockage detection and remediation are undertaken subsequently. This may be further increasing the risk of accidents and economic cost because of excessive operating pressure. 


\section{(3) Pipe system assessment}

Fluid phase change is not the only cause of blockage formation, the mechanical failures of various components of pipe systems can also lead to pipeline blockage. Understanding the pipe system is critical important to detect the at risk potential blockage locations. Estimating the possibility of blockage formation includes several factors like pipeline layout and all fitting distributions. Flow back points, stalled pigs, defective valves, umbilical lead connections, or ruptures in the internal pipeline system are the typical locations that the blockages can form. On the other hand, most of the blockages will form again although they have been mechanically removed, it is of great importance to study historical operating data such as daily production rates, operating conditions, and prior blockage intervals which are variables at the time of blockage formation. Hydrates in gas pipeline are studied to form and deposit in hours, for instance, while the wax or asphaltenes blockage would take several weeks to form under the corresponding operating conditions.

Pipeline blockage can be partially or fully formed based on its cause and the nature of the blockage. The appropriate assessment of the nature of pipeline blockage is ascertained through fluid characterization, which can help select the proper detection method to estimate the location and severity of the pipeline blockage.

\subsection{Literature Review on Blockage Detection}

An accurate estimation, including the location, size and severity of pipeline blockage, would lead to savings in cost and time for the operator. Although some blockage detection methods have been available for years, with continuing development, they are becoming high tech and sophisticated. Based on the detection equipment needed or not, 
the detection methods developed so far can be broadly classified into the following two main groups: (a) physical inspection methods and (b) mathematical models.

\subsubsection{Physical inspection methods}

The objective of physical inspection methods is to estimate and locate the blockage by corresponding detection equipment, primarily including isotope tracking inspection, densitometry measurement, and acoustic reflectometry.

(1) Isotope tracking inspection

According to the fluid continuity equation, the area with higher velocity indicates restriction. This technology involves the injection of an isotope into the pipeline and subsequently their movements are tracked using the detecting device. The operating data recorded by the tracking device actually indicates the velocity of the isotope along with the fluid which in return indicates the possible location and diameter of the blockage. This isotope method was firstly used by Maclntyre (1959), Wagner et.al. (1961) to visualize the cardiac blood pool. After decade's development, the isotope inspection method has become popular tools in industry. Charlton et.al. (1981) helped find the outstanding isotope that much easier to be tracked for the detecting device. Kasban (2010) also applied the isotope method for detecting blockage or leakage along the pipeline.

(2) Densitometry method

Base on the assessment of the blockage characterization, the densities of blockage formed by hydrate, wax, asphaltene, or scales are of great difference between each other. Densitometry method is that detecting the density of the fluid at some pipeline intervals or cross sections by the specific scanning device. The differences in the densities along the flow path indicates the possible location of the blockage. While the differences in densities 
between the blockage and the transported fluid also affect the accuracy of this detection method. For example, the density of hydrate blockage is close to the density of water which may be difficult to differentiate these two kinds of blockages (Detta et.al, 2016). However, engineering field experience coupled with the information about the fluid property and operating parameters would help in estimating the existence and location of the blockage.

(3) Acoustic reflectometry

This technology involves the introduction of a pulse of sound in-to the pipeline by the acoustic pulse generator. When the acoustic pulse encounters the blockage, reflection is produced and passes along the pipe. The pulse signal is measured by acoustic sensors that are installed outside of the pipe, and then the information can be used to plot a noise profile along the whole pipe. Deviations from the baseline profile indicate the location of pipeline blockage. Theoretical and experimental work about acoustic reflectometry was first proposed by Parker (1981) who studied the correlation between acoustic pulse and background noise, hence developed approach that very small acoustic signals to noise ratio could be detected even for long-distance pipeline. Acoustic techniques were originally used for leakage detection in pipeline (Watanabe et. al. 1986, 1987a). Koyama et.al. (1990) applied acoustic technique for the location and severity of blockage in the pipeline. Also Wang et.al. (2009) performed an experiment in 16-m long PVC pipeline by acoustic methods to detect blockage. The reflected acoustic signals were recorded using matched filters to overcome the influence of background noise.

Apart from these detection techniques, other physical inspection methods such as diameter measurement, radar and sonar technology, thermography method and gamma ray scanning are also used in the detection of the blockage. Physical inspection method can 
estimate the existence and locate the position of blockage directly and accurately by detecting devices while in return it increases the operating cost significantly at the expense of possible shutting down operation and cannot monitor the pipeline network operating continuously.

\subsubsection{Mathematical models}

Mathematical model utilizes the mass conservation, momentum conservation, energy balance equation coupled with the operating parameters such as temperature, pressure, flow rate to estimate the existence and location of blockage. Compared with physical inspection methods, mathematical models have the advantage of quick evaluation at lower cost and can monitor the pipeline continuously without interrupting pipeline operations especially in some harsh environments like deep water, polar area or areas with higher difficulty in accessing. Mathematical models primarily include backpressure technology, pressure transient pulse technology, frequency response method and dimensionless method.

(1) Backpressure technology

This method involves a multi-flowrate experiment undertaken which establishes a baseline profile of pressure drop versus flow rate. Deviations from this profile indicates the possible existence and location of blockage. This technology has long been recognized as an efficient method for detecting blockages in pipeline. Scott and Satterwhite (1998) considered the application of backpressure method as a method monitoring the growth of blockage in gas pipeline and firstly proposed the blockage factor to estimate the location of blockage. Scott and Yi (1999) also applied this method in liquid flow lines while this method only helps in rough estimation because the effects of length and size of the 
blockage are coupled together. Liu and Scott $(2000,2001)$ proposed the average pressure method based on backpressure technology to locate the partial blockage in the pipeline. This new method requires three different tests: steady-state back-pressure test that is identical to backpressure method taken to determine the blockage factor; simultaneous shut-in test to obtain the average pressure; bleed-off test to determine the volume factor that indicates the location of pipeline blockage.

(2) Pressure transient technology

This technology involves the generation and transmission of pressure pulse through the liquid medium along the pipeline. The time delay between the pressure pulse and the echoes received by the topside receiver is used to locate the position of blockage with reasonable precision. Vitkovsky (2003) sent an impulse generated by the movement of the valve shut down the pipeline to detect the location of blockage which also can be used for leakage detection. Adewumi et.al. (2003) proposed a one-dimensional model based on the pressure transient method to describe the propagation of a pressure pulse through a pipe under different scenarios like no blockage, single blockage and multiple blockages cases. Chen et al. (2007) proposed a 1D representation model to investigate the characteristics of the pressure wave propagation process through a pipe with blockage. Besides, this model can be applied to estimate the blockage location, length and severity in single or multiphase pipeline. Adeleke et al. (2012) proposed a single phase, isothermal gas model that taking viscous effects into account when detecting blockage. The viscous losses have no effect on blockage length and location prediction accuracy but has significant impact on the accuracy of blockage severity predictions.

(3) Frequency response method 
This method involves the introduction of pressure pulse generated by opening and closing a valve periodically. The procedure is repeated for a range of frequency and the amplitude of the pressure fluctuations at the location of the oscillating valve is analyzed by using the transfer matrix method. The comparison between peak pressure frequency responses indicates the location and size of partial blockage. A frictionless model based on frequency response was proposed by Mohapatra (2006) to characterize the location and the size of blockage. Especially when the pre- and post-frequency development of a pipeline is known, this model can be used to detect the location and the size of additional partial blockage. Lee et.al. (2008) found that discrete blockages were influenced by the frequency peaks on an oscillatory pattern by analyzing the behavior of the pipeline in the form of a frequency response diagram. He also pointed out this method can be extended to situations that some with unknown operating parameters. Duan et al. (2011) proposed a detection model of blockages in water pipeline by analyzing the occurrence of the resonant peaks in the frequency axis.

\subsubsection{Comparison of detection methods}

The merits and demerits of these above-mentioned methods are also discussed in Table 1.1. And the comparison of applicability of different methods is given in Table 1.2. 
Table 1.1 Merits and demerits of different detection methods

\begin{tabular}{|c|c|c|c|}
\hline \multicolumn{2}{|c|}{ Detection methods } & Merits & Demerits \\
\hline \multirow{3}{*}{$\begin{array}{l}\text { Physical } \\
\text { Inspection } \\
\text { methods }\end{array}$} & $\begin{array}{c}\text { Isotope tracking } \\
\text { inspection }\end{array}$ & $\begin{array}{l}\text { - Be effective in detecting the locations and sensitivity } \\
\text { of blockages in partially blocked pipelines. }\end{array}$ & $\begin{array}{l}\text { Be more challenging based on the pipeline design, } \\
\text { i.e. pipe in pipe or for buried pipelines are similar to } \\
\text { those noted for the densitometry technique. }\end{array}$ \\
\hline & $\begin{array}{c}\text { Densitometry } \\
\text { method }\end{array}$ & $\begin{array}{l}\text { - This method can be repeated multiple times -to predict } \\
\text { the blockage location with an increased level of } \\
\text { confidence. }\end{array}$ & $\begin{array}{l}\text { - Be more challenging based on the pipeline design, } \\
\text { i.e. pipe in pipe, buried pipes. } \\
\text { - The density of some of the typical pipeline contents } \\
\text { are very close. }\end{array}$ \\
\hline & $\begin{array}{l}\text { Acoustic } \\
\text { reflectometry }\end{array}$ & $\begin{array}{l}\text { - Methodology is economical, proficient to identify } \\
\text { blockages and holes in pipe as small as } 1 \% \text { of its } \\
\text { diameter }\end{array}$ & $\begin{array}{l}\text { - To monitor longer pipelines, a large number of } \\
\text { acoustic sensors are needed. } \\
\text { - Small blockages whose acoustic signal is small and } \\
\text { only differ slightly from the background noise cannot } \\
\text { be detected. }\end{array}$ \\
\hline \multirow[t]{2}{*}{$\begin{array}{c}\text { Mathematical } \\
\text { models }\end{array}$} & $\begin{array}{c}\text { Backpressure } \\
\text { technology }\end{array}$ & $\begin{array}{l}\text { - This method can be used to provide important } \\
\text { information for monitoring chemical inhibition } \\
\text { programs, scheduling pigging, assessing risk for } \\
\text { pigging and planning other intervention procedures. }\end{array}$ & $\begin{array}{l}\text { - The higher pressure drop is more preferable to a } \\
\text { lower overall pressure drop for locating the blockage } \\
\text { because with limitation of pressure gauge the } \\
\text { location result may be questionable. } \\
\text { - The subtle difficulty in using this method lies in the } \\
\text { establishment of the baseline, which requires a time- } \\
\text { consuming multi-rate test. }\end{array}$ \\
\hline & $\begin{array}{l}\text { Pressure } \\
\text { transient } \\
\text { technology }\end{array}$ & $\begin{array}{l}\text { - This method is remote, non-intrusive and efficient. } \\
\text { - No additional instrument other than a dynamic } \\
\text { pressure gauge is needed. }\end{array}$ & $\begin{array}{l}\text { In the case of hydrate blockages, the addition of } \\
\text { liquid head and pressure pulsing may aggravate the } \\
\text { blockage situation. }\end{array}$ \\
\hline
\end{tabular}




\begin{tabular}{|c|c|c|c|}
\hline & & & - $\quad$ The blockage severity is usually underestimated. \\
\hline & $\begin{array}{l}\text { Frequency } \\
\text { response method }\end{array}$ & $\begin{array}{l}\text { - The flow variables at only one location are sufficient to } \\
\text { predict the blockage. } \\
\text { - The methodology is simple and is economical. } \\
\text { - The PPFR can be used to estimate the location and the } \\
\text { size of the blockage. }\end{array}$ & $\begin{array}{l}\text { - Decision on the range of frequencies should take into } \\
\text { account the safety of the system and constraints on } \\
\text { valve operation. } \\
\text { - Valve operation continuous opening and closing may } \\
\text { require specialized instrumentation. } \\
\text { - The fluctuation of valve opening should be kept low, } \\
\text { say about } 0.1 \text { so that the linearity assumption is not } \\
\text { violated. }\end{array}$ \\
\hline
\end{tabular}

Table 1.2 Applicability of different methods

\begin{tabular}{|c|c|c|c|c|c|c|c|}
\hline \multirow[b]{2}{*}{ Detection methods } & \multicolumn{3}{|c|}{ Type of fluid } & \multirow[b]{2}{*}{ Nature of blockage } & \multicolumn{3}{|c|}{ Blockage Diagnosis } \\
\hline & $\begin{array}{l}\text { High density(e.g. } \\
\text { Water) }\end{array}$ & $\begin{array}{c}\text { Medium } \\
\text { density(e.g. Oil) }\end{array}$ & $\begin{array}{c}\text { Low density } \\
\text { (e.g. Gas) }\end{array}$ & & Location & length & diameter \\
\hline $\begin{array}{l}\text { Isotope tracking } \\
\text { inspection }\end{array}$ & $\sqrt{ }$ & $\sqrt{ }$ & $\sqrt{ }$ & All & $\sqrt{ }$ & $\sqrt{ }$ & \\
\hline Densitometry method & $\sqrt{ }$ & $\sqrt{ }$ & $\sqrt{ }$ & All & $\sqrt{ }$ & $\sqrt{ }$ & $\sqrt{ }$ \\
\hline Acoustic reflectometry & $\sqrt{ }$ & $\sqrt{ }$ & $\sqrt{ }$ & All & $\sqrt{ }$ & $\sqrt{ }$ & \\
\hline $\begin{array}{c}\text { Backpressure } \\
\text { technology }\end{array}$ & $\sqrt{ }$ & $\sqrt{ }$ & $\sqrt{ }$ & All & $\sqrt{ }$ & $\sqrt{ }$ & \\
\hline $\begin{array}{c}\text { Pressure transient } \\
\text { technology }\end{array}$ & $\sqrt{ }$ & $\sqrt{ }$ & $\sqrt{ }$ & Non-hydrate blockages & $\sqrt{ }$ & $\sqrt{ }$ & $\sqrt{ }$ \\
\hline $\begin{array}{c}\text { Frequency response } \\
\text { method }\end{array}$ & $\sqrt{ }$ & $\sqrt{ }$ & $\sqrt{ }$ & $\begin{array}{c}\text { All including Single and } \\
\text { two blockages }\end{array}$ & $\sqrt{ }$ & $\sqrt{ }$ & \\
\hline
\end{tabular}




\subsection{Objectives and Organization of the Thesis}

Pipeline blockage can occur anywhere in the pipeline and is of higher difficulty to be detected accurately in the pipe over long distance. Early assessment of pipeline blockage can improve the effectives and the reliability of pipeline operation. Therefore, the objectives of this research are:

(1) To analyze the relationship between the pressure distribution through the pipeline and the blockage characterizations based on computational fluid dynamic (CFD) simulations.

(2) To study the effects of blockage characterizations including blockage inner diameter, blockage length and blockage location on the pressure drop through the pipeline.

(3) Based on the orthogonal array testing (OAT) technique and the introduction dimensionless parameters like dimensionless pressure drop, dimensionless inner diameter, dimensionless length and dimensionless location, a prediction mathematical model of pipeline blockage detection is proposed and could be used to get the first evaluation of pipeline blockage like location and length with much lower cost compared with physical inspection method.

(4) To validate this prediction model, lab experiments under various blockage characterizations were run.

This thesis is laid out as follows. After this introduction, the relevant CFD simulation method and corresponding pressure distribution through the pipeline without/with the blockage are introduced in Chapter II. This is followed by the investigation of effects of blockage characterizations on the pressure drop through pipeline and the introduction of blockage prediction model based on the dimensionless analysis in 
Chapter III. Chapter IV describes the set-up procedure of lab experiment and the corresponding results which could be used to validate the blockage prediction model. Finally, the main conclusions and future works are drawn in Chapter V. 


\section{CHAPTER II}

\section{CFD SIMULATION METHOD OF PIPELINE BLOCKAGE}

Numerical simulation can provide information on the hydrodynamics of pipeline fluid in detail, which is not easy to obtain by laboratory experiments (Yadav, 2013; Arpino. F, 2009; Jalilinasrabady, 2013). Therefore, ANSYS (R.18.1) CFD (computational fluid dynamic) package is used to investigate the pressure distribution through the pipeline with/without the blockage.

\subsection{Governing Equations}

Oil is_treated as an_incompressible fluid. And there is no phase change and no-slip between fluids at the interface of the fluids. The flow of fluid is governed by the RANS (Reynolds-Averaged-Navier-Stokes) equations, including the mass and momentum equations written as follows:

\subsubsection{Mass conservation}

This equation is the general form of the mass conservation equation and is valid for incompressible as well as compressible flow. The source $S_{m}$ is the mass added to the continuous phase from the dispersed second phase (for example, due to vaporization of liquid droplets) and any user-defined sources.

$$
\frac{\partial p}{\partial t}+\nabla \cdot(\rho \vec{v})=S_{m}
$$

\subsubsection{Momentum conservation}

Conservation of momentum is an internal reference frame is described by: 


$$
\frac{\partial}{\partial t}(\rho \vec{v})+\nabla \cdot(\rho \vec{v} \vec{v})=-\nabla p+\nabla \cdot(\overline{\bar{\tau}})+\rho \vec{g}+\vec{F}
$$

where $p$ is the static pressure, $\rho \vec{g}$ and $\vec{F}$ are the gravitational body force and external body force, respectively. $\overline{\bar{\tau}}$ is the stress tensor which described by this equation:

$$
\overline{\bar{\tau}}=\mu\left[\left(\nabla \vec{v}+\nabla \vec{v}^{T}\right)-\frac{2}{3} \nabla \cdot \vec{v} I\right]
$$

where $\mu$ is the molecular viscosity, $I$ is the unit tensor, and the second term on the righthand side is the effect of volume dilation.

\subsubsection{Transport equations for the standard $k-\varepsilon$ model}

The standard k- $\varepsilon$ model is a model based on transport equations for the turbulence kinetic energy $(k)$ and its dissipation rate $(\varepsilon)$. In the derivation of the k- $\varepsilon$ model, the assumption is that the flow is fully turbulent, and the effects of the molecular viscosity are negligible. The standard $\mathrm{k}-\varepsilon$ model is therefore valid only for fully turbulent flows. The kinetic energy, $k$, and its rate of dissipation, $\varepsilon$, are obtained from the following equations:

$$
\begin{gathered}
\frac{\partial}{\partial t}(\rho k)+\frac{\partial}{\partial x_{i}}\left(\rho k u_{i}\right)=\frac{\partial}{\partial x_{j}}\left[\left(\mu+\frac{\mu_{t}}{\sigma_{k}}\right) \frac{\partial k}{\partial x_{j}}\right]+G_{k}-\rho \varepsilon+S_{k} \\
\frac{\partial}{\partial t}(\rho \varepsilon)+\frac{\partial}{\partial x_{i}}\left(\rho \varepsilon u_{i}\right)=\frac{\partial}{\partial x_{j}}\left[\left(\mu+\frac{\mu_{t}}{\sigma_{\varepsilon}}\right) \frac{\partial \varepsilon}{\partial x_{j}}\right]+C_{1 \varepsilon} G_{k} \frac{\varepsilon}{k}-C_{2 \varepsilon} \rho \frac{\varepsilon^{2}}{k}+S_{\varepsilon}
\end{gathered}
$$

where the turbulent (or eddy) viscosity, $\mu_{t}$, is calculated by combining $\mathrm{k}$ and $\varepsilon$ as follows:

$$
\mu_{t}=\rho C_{\mu} \frac{k^{2}}{\varepsilon}
$$

$G_{k}$ represents the generation of turbulence kinetic energy due to the mean velocity gradients, calculated as described by:

$$
G_{k}=-\rho \overline{u_{\imath}^{\prime} u_{\jmath}^{\prime}} \frac{\partial u_{j}}{\partial x_{i}}
$$

$S_{k}$ and $S_{\varepsilon}$ are user-define source terms. $C_{1 \varepsilon}, C_{2 \varepsilon}$ and $C_{\mu}$ are constant. $\sigma_{k}$ and $\sigma_{\varepsilon}$ are the turbulent Prandtl numbers for $k$ and $\varepsilon$, respectively. In the standard k- $\varepsilon$ model, all these constants have the following default values (Rodi, 2017): 


$$
C_{1 \varepsilon}=1.44, C_{2 \varepsilon}=1.92, C_{\mu}=0.09, \sigma_{k}=1.0, \sigma_{\varepsilon}=1.3
$$

\subsection{Computational Domain and Mesh}

Under the action of the fluid, the calculations are considered to simulate turbulent flow inside the pipe. Therefore, three-dimensional flow simulation is applied to capture the dynamic features. Figure 2.1 shows the sketches of the geometry for computational domain of the pipeline without/with the blockage studied in this paper. The whole simulation is investigated in a 3D pipeline with a length of $80 \mathrm{in}$. and the ID of 3/4 in. The blockage part has a smaller diameter (1/2 in.) compared with the whole pipe and it starts from the 24 in. position ( 0.3 location) away from the pipe inlet. The detail of the computational parameters is shown in Table 2.1.

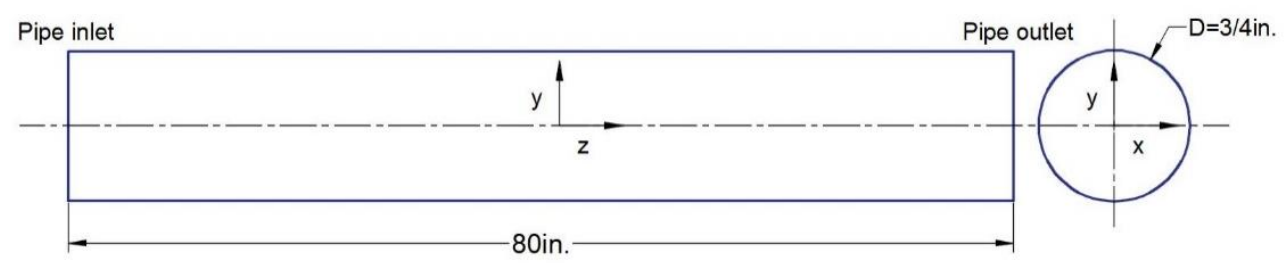

(a)

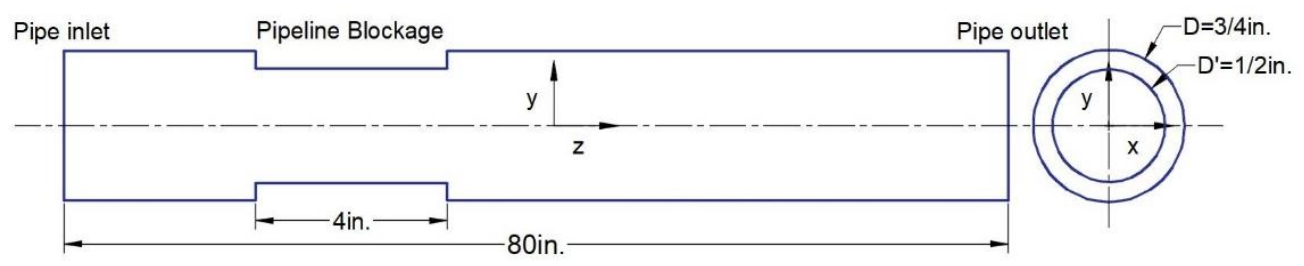

(b)

Figure 2.1 3D computational domain: (a) pipeline without blockage; (b) pipeline with blockage

Table 2.1 CFD computational domain parameters

\begin{tabular}{|c|c|c|c|}
\hline \multicolumn{2}{|c|}{ Pipeline without the blockage } & \multicolumn{2}{c|}{ Pipeline with the blockage } \\
\hline Pipe Diameter/in. & $3 / 4$ & Pipe Diameter/in. & $3 / 4$ \\
\hline Pipe Length/in. & 80 & Pipe Length/in. & 80 \\
\hline
\end{tabular}




\begin{tabular}{|c|c|c|c|}
\hline Blockage Diameter/in. & -- & Blockage Diameter/in. & $1 / 2$ \\
\hline Blockage Length/in. & -- & Blockage Length/in. & 4 \\
\hline $\begin{array}{c}\text { Blockage Location/in. away } \\
\text { from the pipe inlet }\end{array}$ & -- & $\begin{array}{c}\text { Blockage Location/in. away } \\
\text { from the pipe inlet }\end{array}$ & 24 \\
\hline
\end{tabular}

Design Modeler and Mesh modules in ANSYS Workbench are employed to generate the geometry generation and meshing separately. The fluid occupying region is discretized with pyramidal cells and the progressive mesh is used to capture the nearblockage flow properties. A proper grid density is reached by repeating calculations until a suitable independent grid is found. At last, the number of mesh cells used in simulation is about from 350,000 to 440,000 . For the quality parameters of mesh grid, it is recommended to use orthogonal quality or skewness value as quality criteria. It is believed the mesh grid is good while the orthogonal quality is larger than 0.2 or the skewness is less than 0.8. As shown in Figure 2.2, the skewness value of most of the mesh grids are less than 0.22 . Therefore, it should be excellent for the 3D CFD simulation.

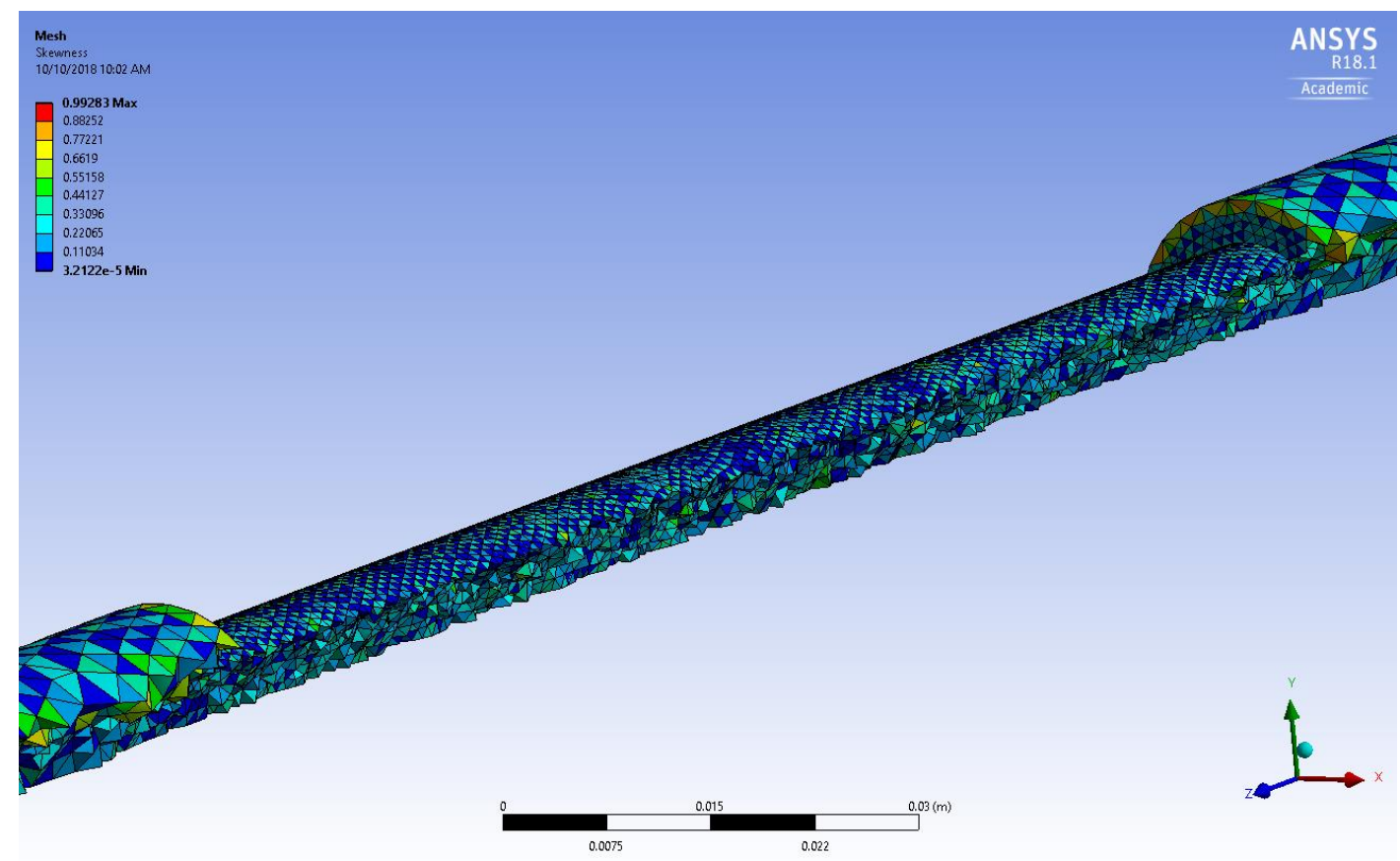

Figure 2.2 3D computational meshing 


\subsection{Solution Method and Boundary Conditions}

The present calculations are performed using ANSYS 18.1 and utilizing the standard k- $\varepsilon$ model. For comparing simulation results with lab experimental results, all the simulations are carried out using water instead of crude oil. In calculations, coupled algorithm is applied to solve the pressure-velocity coupling to satisfy the conservation laws of momentum and mass. In order to obtain better simulation results through the blockage, a second order upwind scheme in space is considered to avoid numerical errors and to ensure accurate numerical solution. The pipe inlet velocity is defined as $\mathrm{v}=0.6 \mathrm{~m} / \mathrm{s}$ at $\mathrm{z}=0$ and the pressure outlet at the end of the pipe is set to $13,800 \mathrm{~Pa}$. The convergent residual in the simulation volume for each equation is smaller than $10^{-5}$.

\subsection{Simulation Results and Discussion}

In order to avoid pipe erosion, the velocity in water pipeline should be less than 3 $\mathrm{m} / \mathrm{s}$. The operating line pressure varies between 0.1 to 5 bars. Due to the investigation of the pressure distribution and the flow behavior along the pipeline blockage, the line pressure is varied because of various operating conditions in this case. The following results are based on the steady-state CFD simulations.

\subsubsection{CFD simulation validation}

In order to validate the $3 \mathrm{D}$ CFD model, more than twenty-four 3D steady state simulations under different blockages conditions have been carried out to study the effect of pressure drop on pipeline flow rate under different pipeline blockage sizes. The simulation result is shown in Figure 2.3. For the four different blockage diameters and lengths, the results indicate that the pipeline flow rate is a function of the square root of the pressure drop (pressure drop coefficient $b \approx 0.5$ ) as $Q=a(\Delta P)^{b}$ where the $Q$ is the pipeline 
flow rate in $\mathrm{L} / \mathrm{s}, \Delta P$ is the pressure drop along the whole pipe in bars and $a$ is a constant. This agrees with the theoretical and experimental single choke flow equation. As the inlet pressure increases for a pipeline with a specific blockage, the pressure drop along this pipe increases and compresses more fluid into the pipeline which results in higher pipeline flow velocity. Besides, as the blockage grows serious (blockage thickness as well as blockage length increases), the pressure drop through the whole pipeline increases because of the decrement of flow area, and the flow rate decreases as the flow area decreases which indicates lower flow rate while the pipeline blockage size increases.

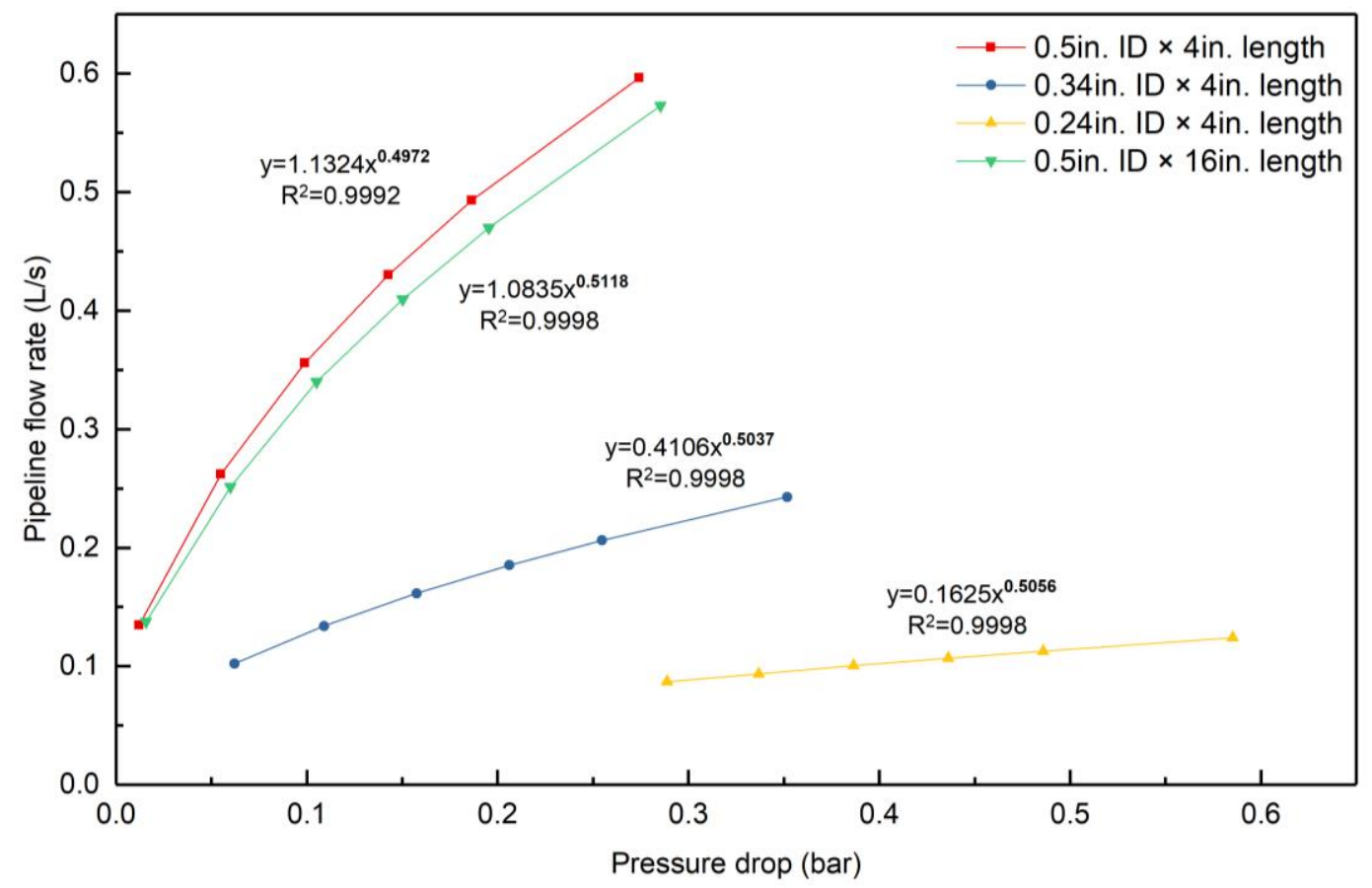

Figure 2.3 CFD simulation of the effect of the pressure drop on pipeline flow rate under different blockage sizes.

\subsubsection{Pressure distribution through the pipeline without blockage}

For the pipeline without blockage, the pressure distribution along the centerline is shown in Figure 2.4. The pressure decreases gradually from $14.4 \mathrm{kPa}$ to $13.3 \mathrm{kPa}$. When it 
comes to pressure gradient distribution, its value almost remains stable as shown in Figure 2.5. Therefore, the reason of pressure drop through the pipeline is mainly resulted from the friction loss.

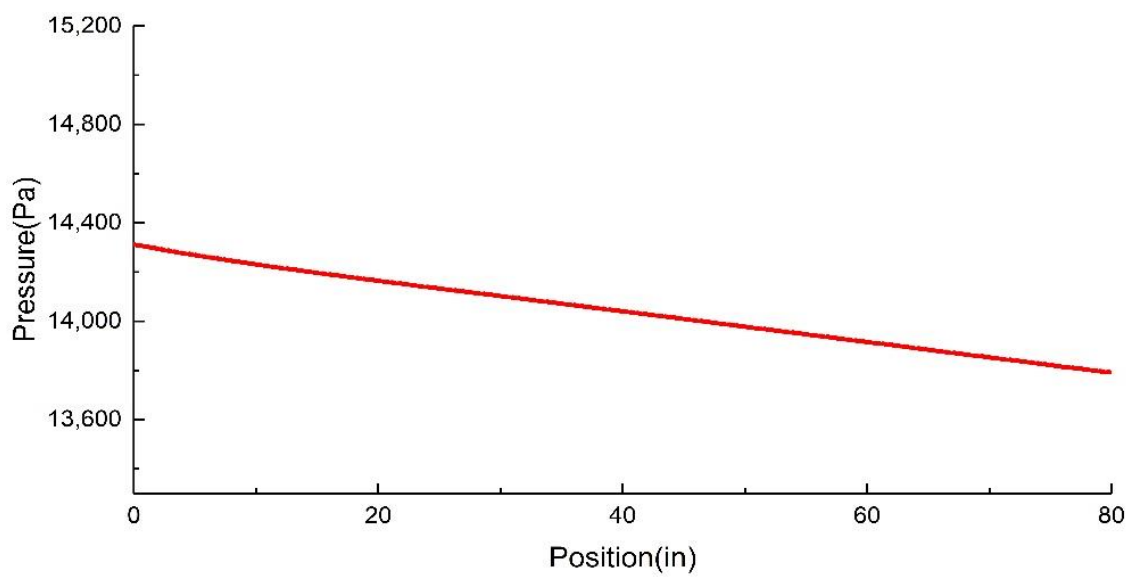

Figure 2.4 Pressure distribution through the pipe centerline without blockage

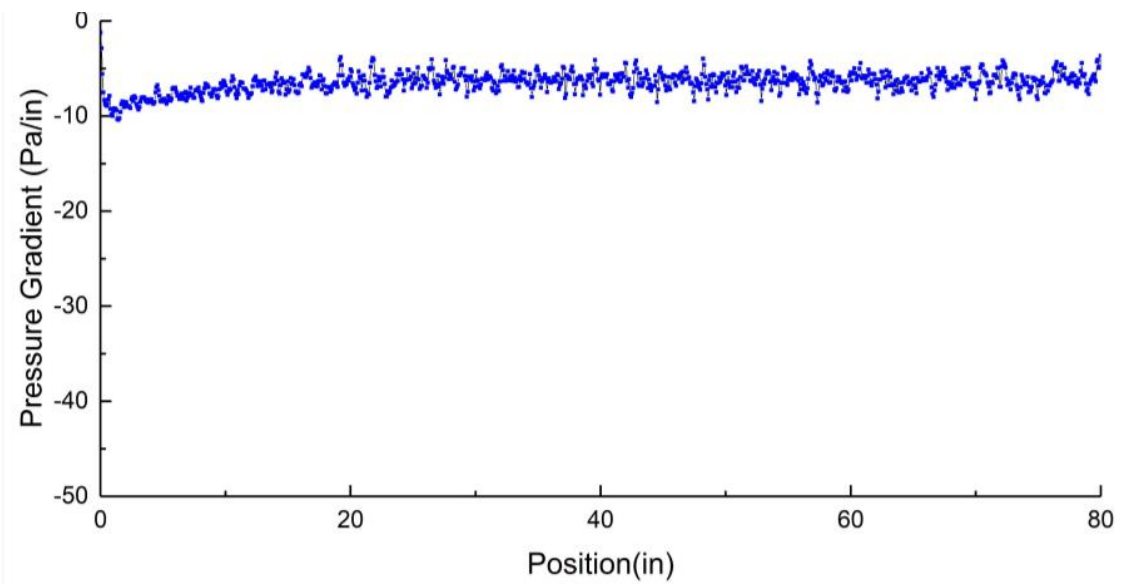

Figure 2.5 Pressure gradient distribution through the pipe centerline without blockage

\subsubsection{Pressure distribution through the pipeline with blockage}

For the pipeline with a blockage, the pressure distribution along the centerline of the pipe is shown in Figure 2.6. It is known that the large pressure differences are located around the inlet and the outlet parts of pipeline blockage. The pressure drop for the whole pipeline is nearly $1.6 \mathrm{kPa}$, which is larger than the pressure drop of pipeline without 
blockage. And there is a dramatic drop of line pressure at the blockage part, which is larger than the pressure drop for the whole pipeline. This feature can also be seen in the pressure gradient distribution. As shown in Figure 2.7, the maximum value of pressure gradient could be $-3600 \mathrm{~Pa} /$ in which greatly threatens the safety operation of pipeline.

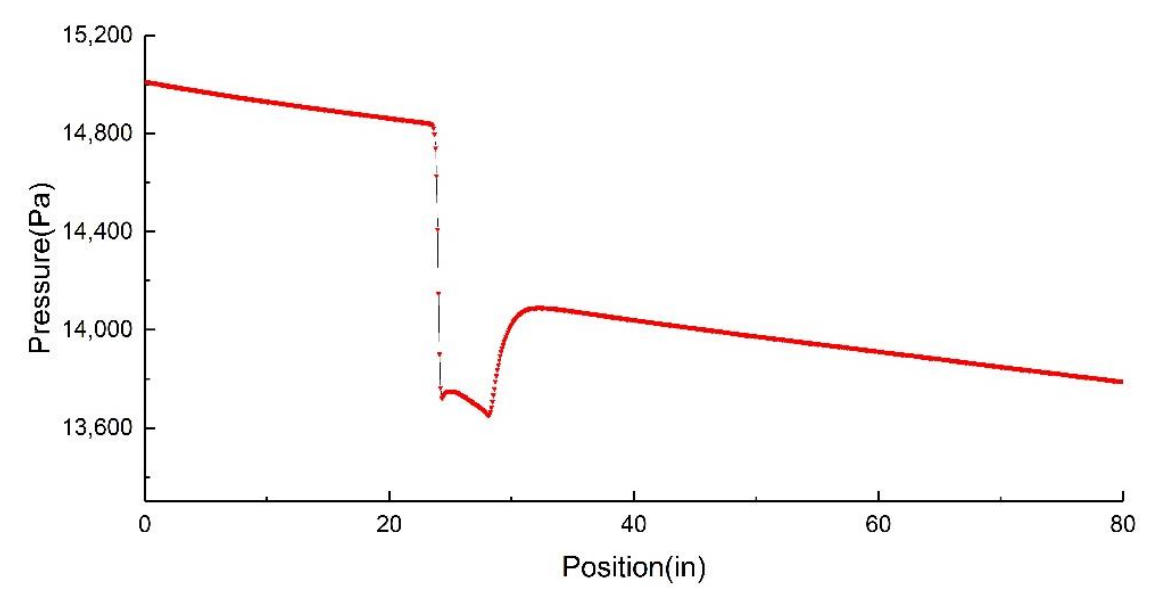

Figure 2.6 Pressure distribution through the pipe centerline with blockage

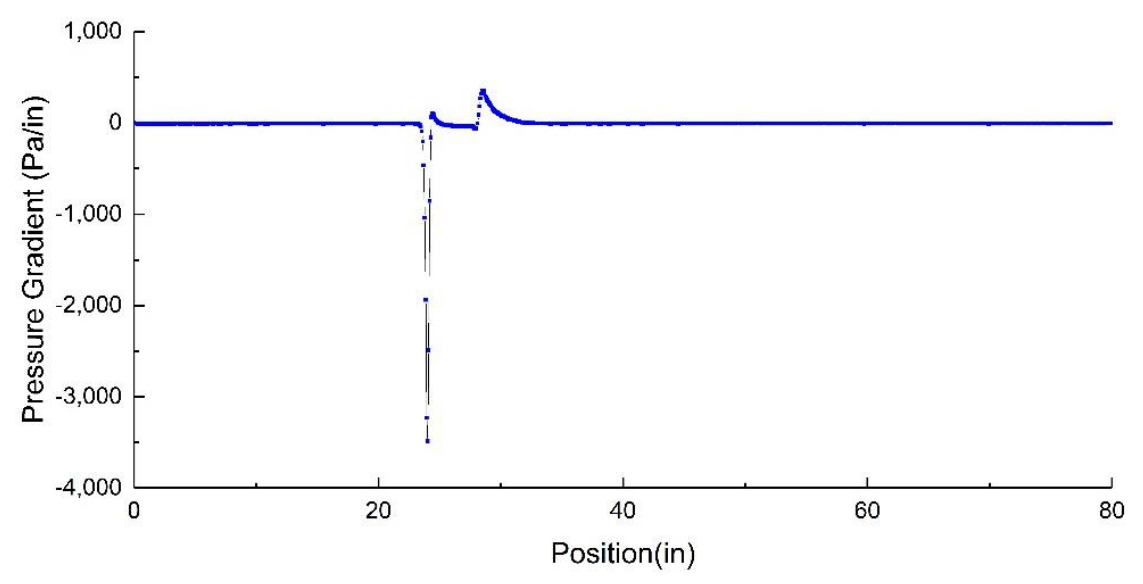

Figure 2.7 Pressure gradient distribution through the pipe centerline with blockage

In order to visualize the pressure distribution around the pipeline blockage, taking three more lines parallel to the centerline and positioned 1,2 and $5 \mathrm{~mm}$ directly below the blockage boundary. The figure is shown in Figure 2.8. This figure presents that the pipeline pressure begins to decrease dramatically very close to the blockage inlet from $150 \mathrm{kPa}$ to 
$135 \mathrm{kPa}$, then, increase downstream pressure of the blockage reaching back to $140 \mathrm{kPa}$. Besides, a sudden decrease in pressure is followed by a slight increase in the blockage inlet part. As one moves from the centerline to the line below $1 \mathrm{~mm}$ the blockage boundary, this pressure distribution kink is becoming more noticeable. This kink is directly caused by the blockage. On the basic of Bernoulli's equation, a sudden increase in the pressure distribution is usually caused by a sudden reduction of the flow area.
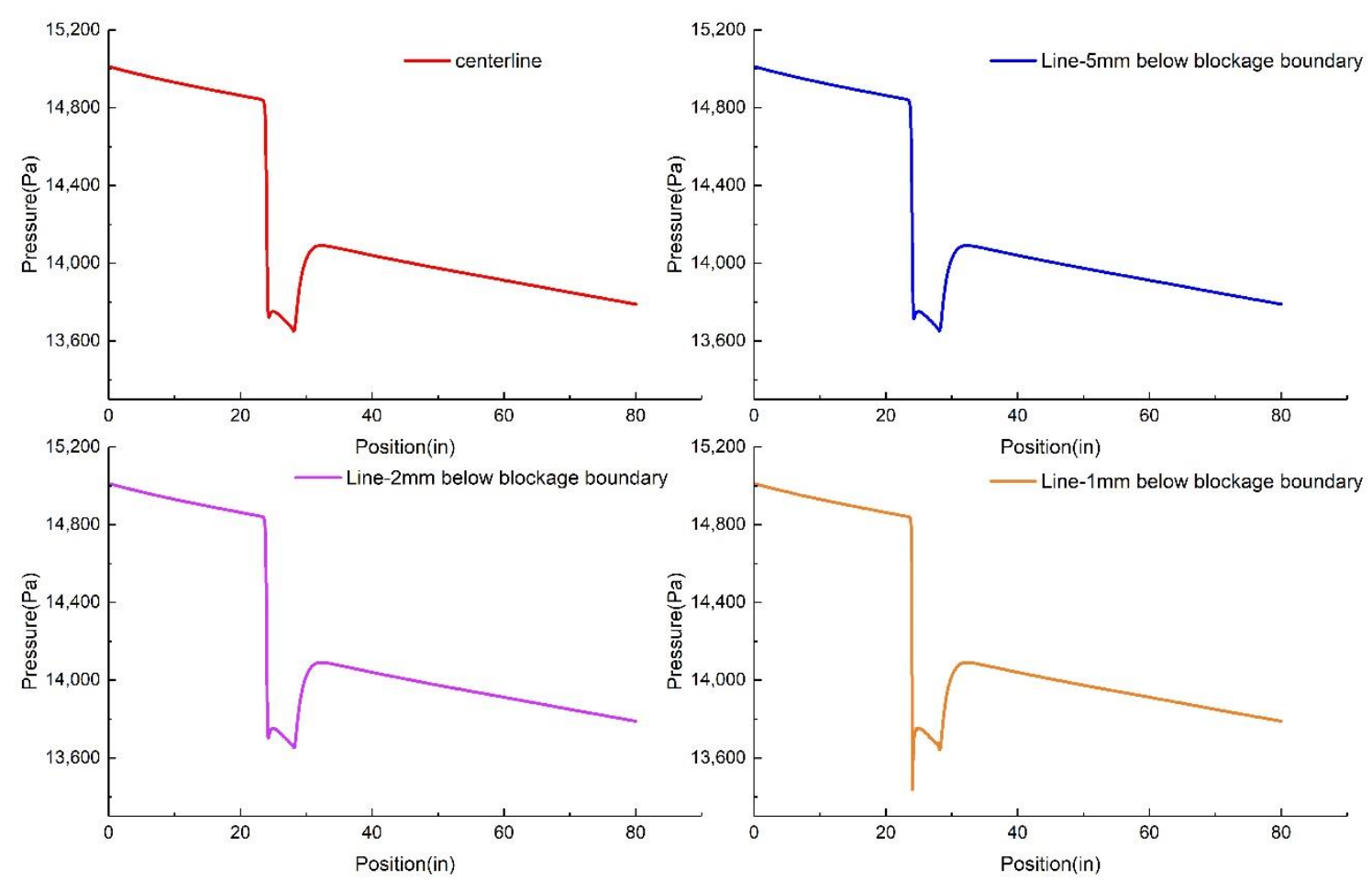

Figure 2.8 Pressure distribution along lines below the blockage boundary

Another way to visualize the pressure kink through the pipeline blockage is to look at the pressure gradient as shown in Figure 2.9. This figure presents the pressure gradient contour of blockage inlet part in the $x-y$ plane and shows values of pressure gradient ranging from around $8.5 \times 10^{-3}$ to around $1.4 \times 10^{3} \mathrm{~Pa} / \mathrm{in}$. 


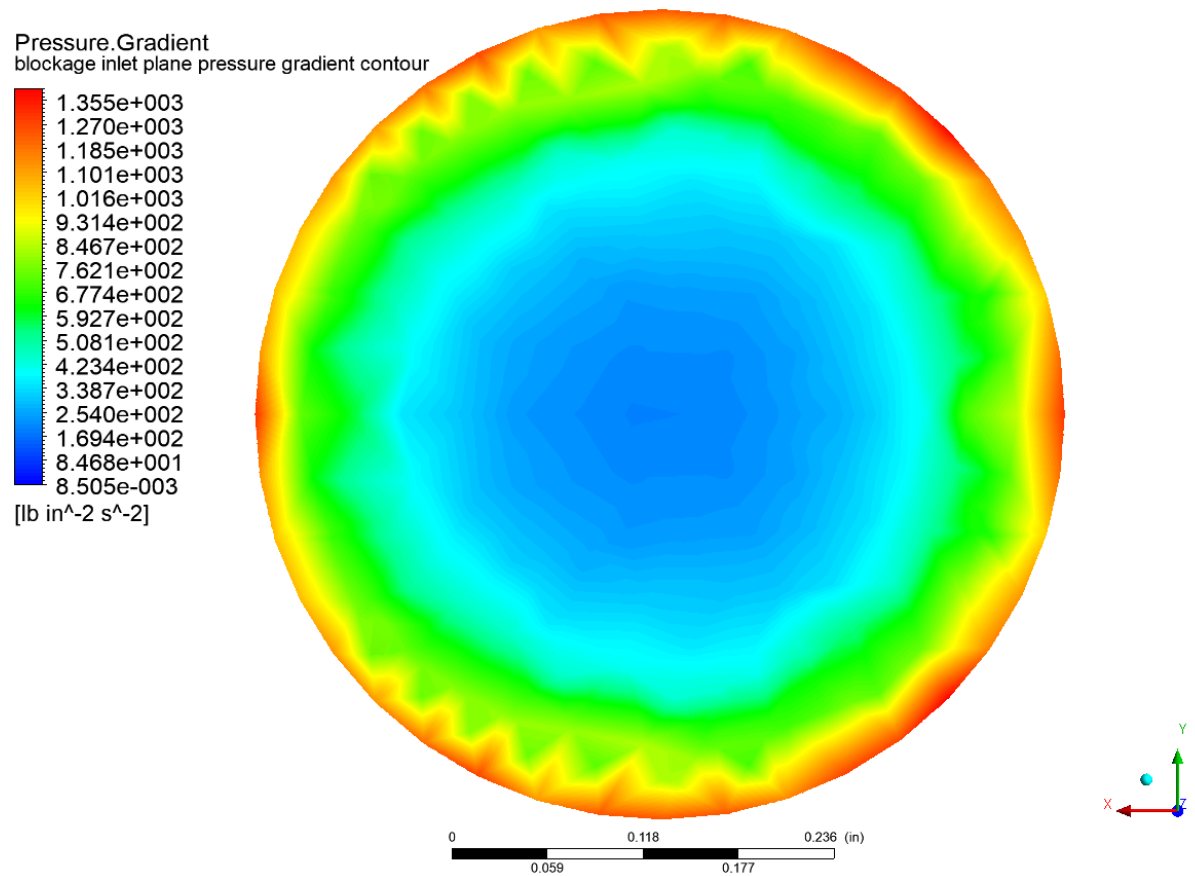

Figure 2.9 Zoom-in view of pressure gradient contour of blockage inlet part.

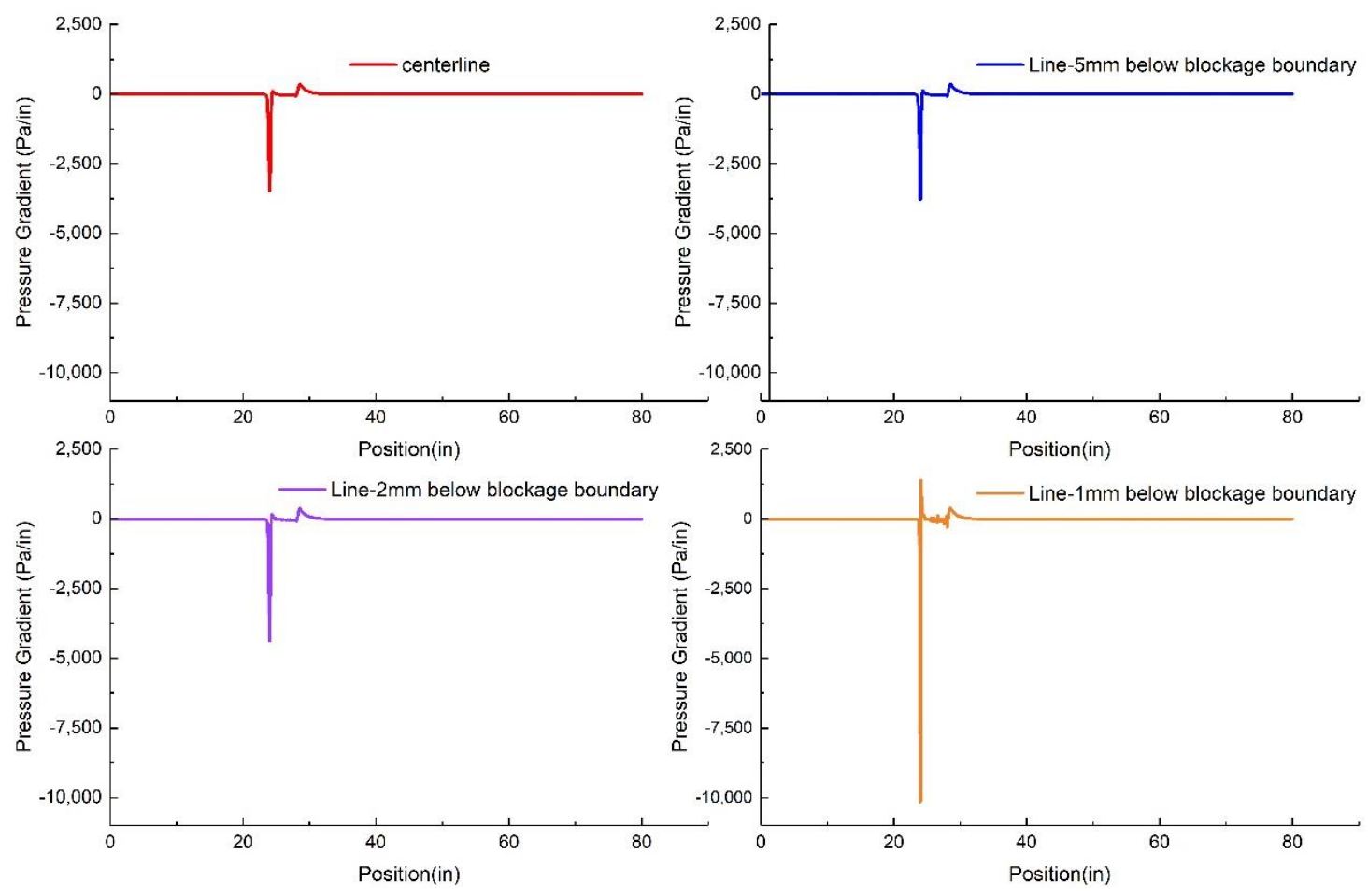

Figure 2.10 Pressure gradient distribution along lines below the blockage boundary 
In order to show the variations of pressure gradient along the whole pipe, lines parallel to the centerline and positioned 1,2 and $5 \mathrm{~mm}$ directly below the blockage boundary are chosen to present the pressure gradient, as shown in Figure 2.10. It turns out that this pressure gradient is almost constant along the pipe except the blockage section. The pressure gradient decreases sharply once entering the blockage and the pressure gradient becomes greater as it is close to the blockage boundary. While reaching the blockage outlet, the pressure gradient increases a little bit compared with the blockage inlet part. Hence, considering a non-intrusive method to measure the pressure or the pressure gradient through the pipeline, could make it possible to sense the existence of blockage and detect its location.

The kinetic energy of turbulence was calculated for studying the influence of blockage on the fluid turbulence. Figure 2.11 shows the contours around the blockage inlet part. It presents that the kinetic energy in vicinity of the blockage is almost 400 times in comparison to the normal levels across the pipe. This shows a high increase of turbulence in vicinity of the blockage.

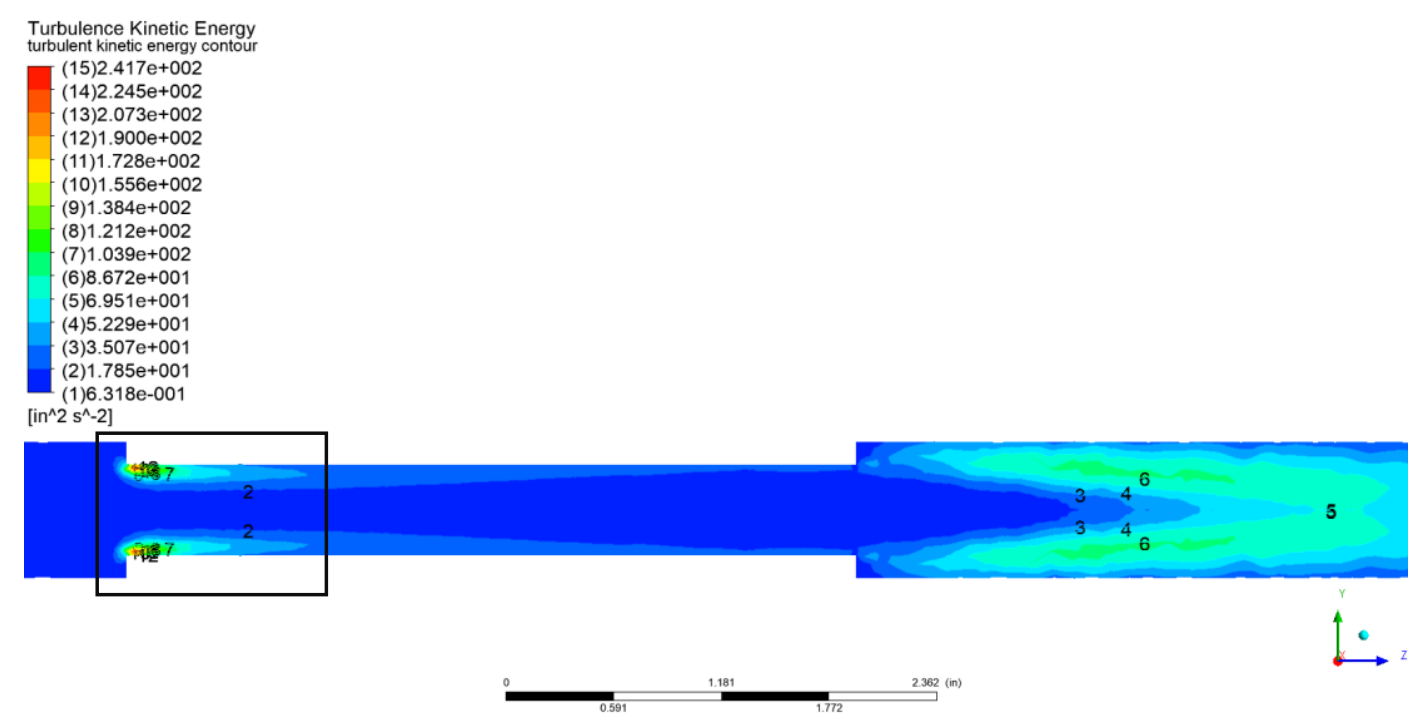

(a) 


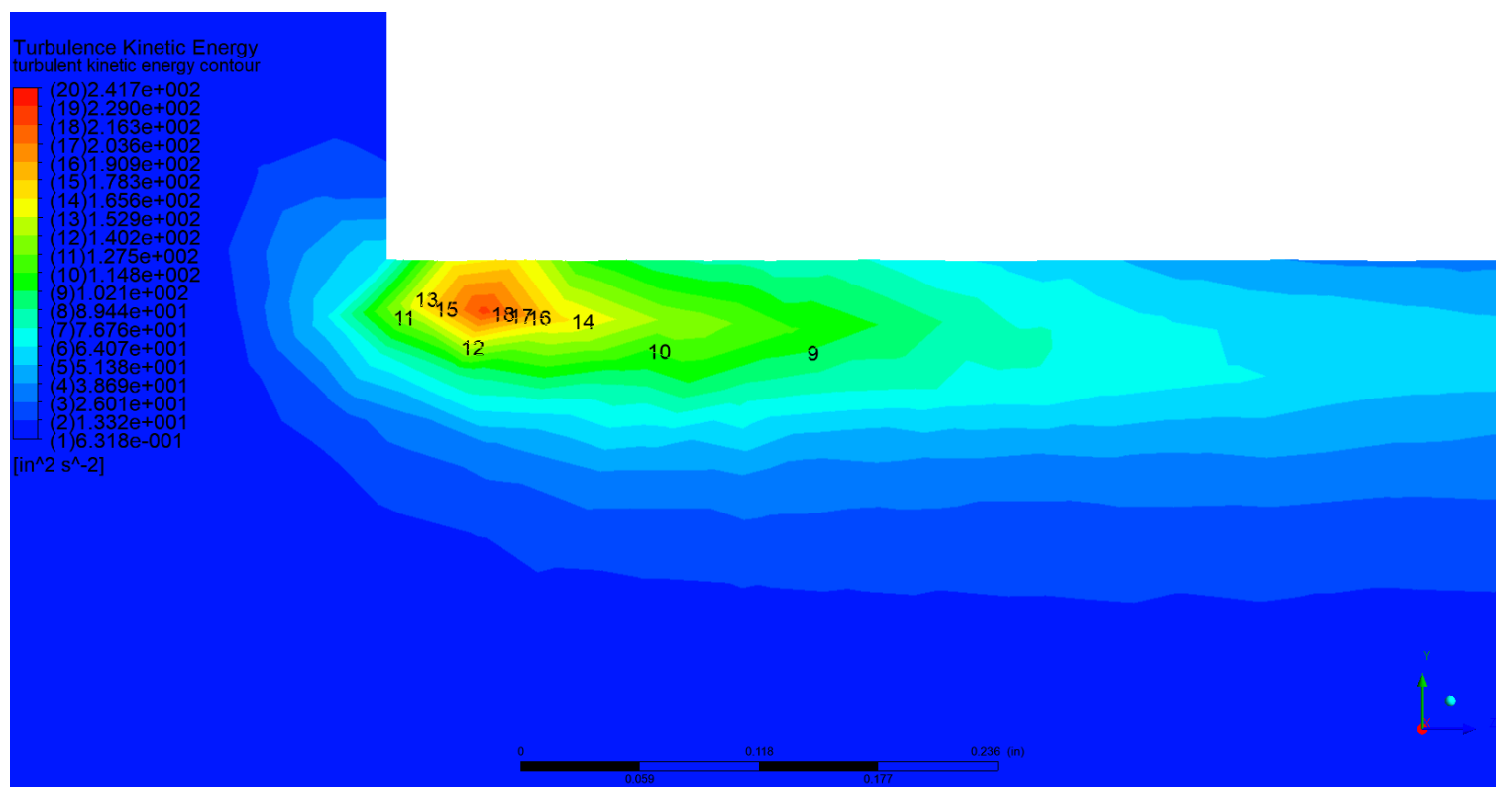

(b)

Figure 2.11 Contours of turbulent kinetic energy around the blockage 


\section{CHAPTER III}

\section{EFFECTS OF BLOCKAGE CHARACTERIZATION ON PRESSURE DISTRIBUTION AND DIMENSIONLESS ANALYSIS}

By conducting a series of CFD simulations, effects of blockage location, blockage ID (inner diameter) and blockage length on the pressure distribution through the pipeline are examined. Then, the Orthogonal Array Testing (OAT) technique is applied to study the net impact of every blockage factor on the pipeline pressure distribution. Finally, several dimensionless parameters are introduced to describe the blockage prediction model.

\subsection{Effects of the Blockage Characterizations on Pressure Distribution}

\subsubsection{Effect of blockage location in vicinity of the blockage}

To study the effect of blockage location, a set of CFD simulations are executed to investigate the effect of blockage length on the pressure and its gradient distribution along the whole pipeline. In order to facilitate comparative analysis, four different blockage locations, 8 in, 24 in, 40 in and 56 in away from the pipeline inlet, are taken in CFD simulations while the rest parameters remain same as those in Table 2.1. Figure 3.1 illustrates the results of pressure distribution at different locations. It can be noted that there is no significant difference at pressure drop even though the pressure distribution varies at different locations. In order to present the details, the pressure gradient distribution through the pipeline blockage was calculated and was shown in Figure 3.2. It is noted that pressure gradients almost stay same expect for the distributed location. 

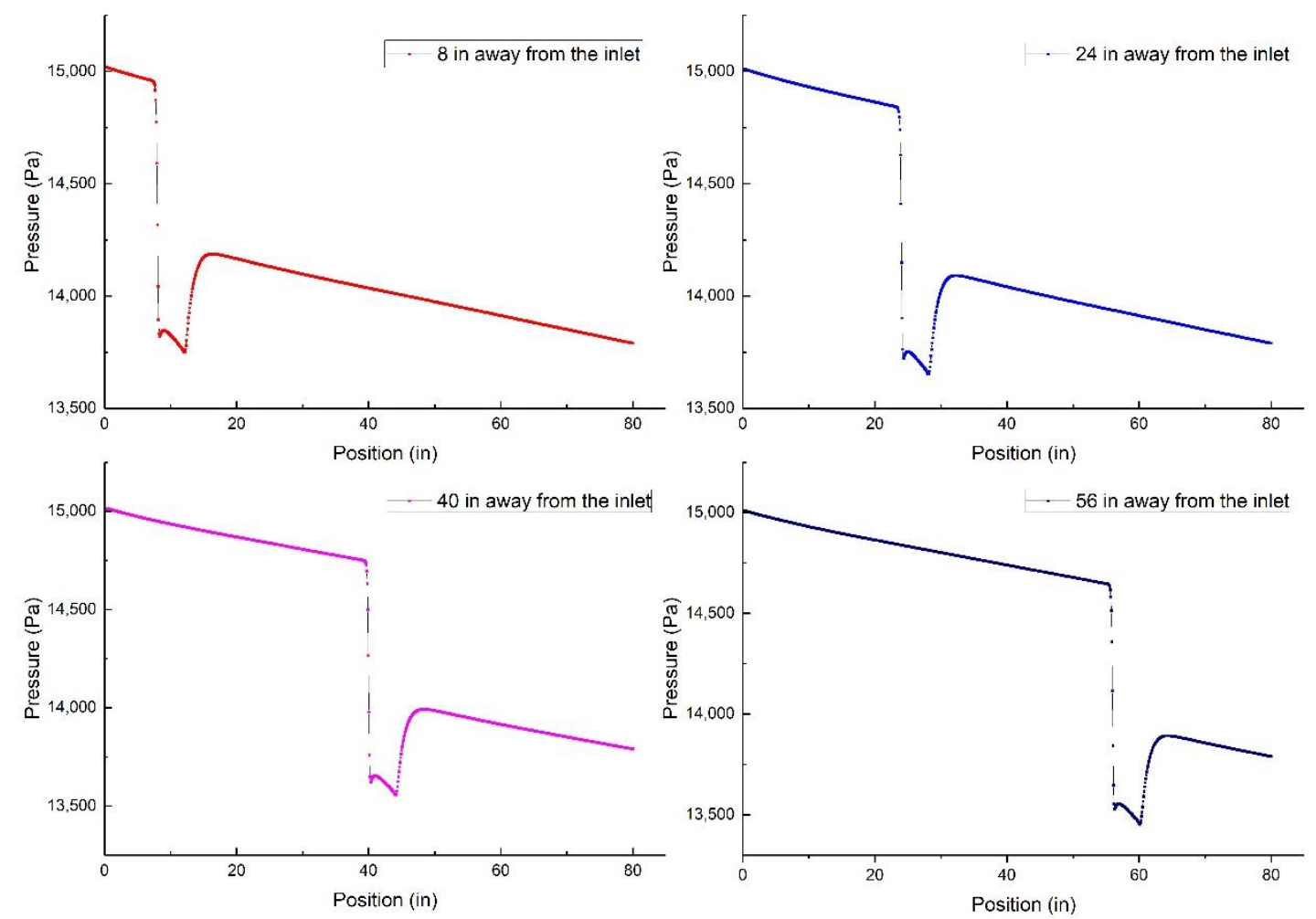

Figure 3.1 Pressure distribution through the pipeline with blockage in various locations
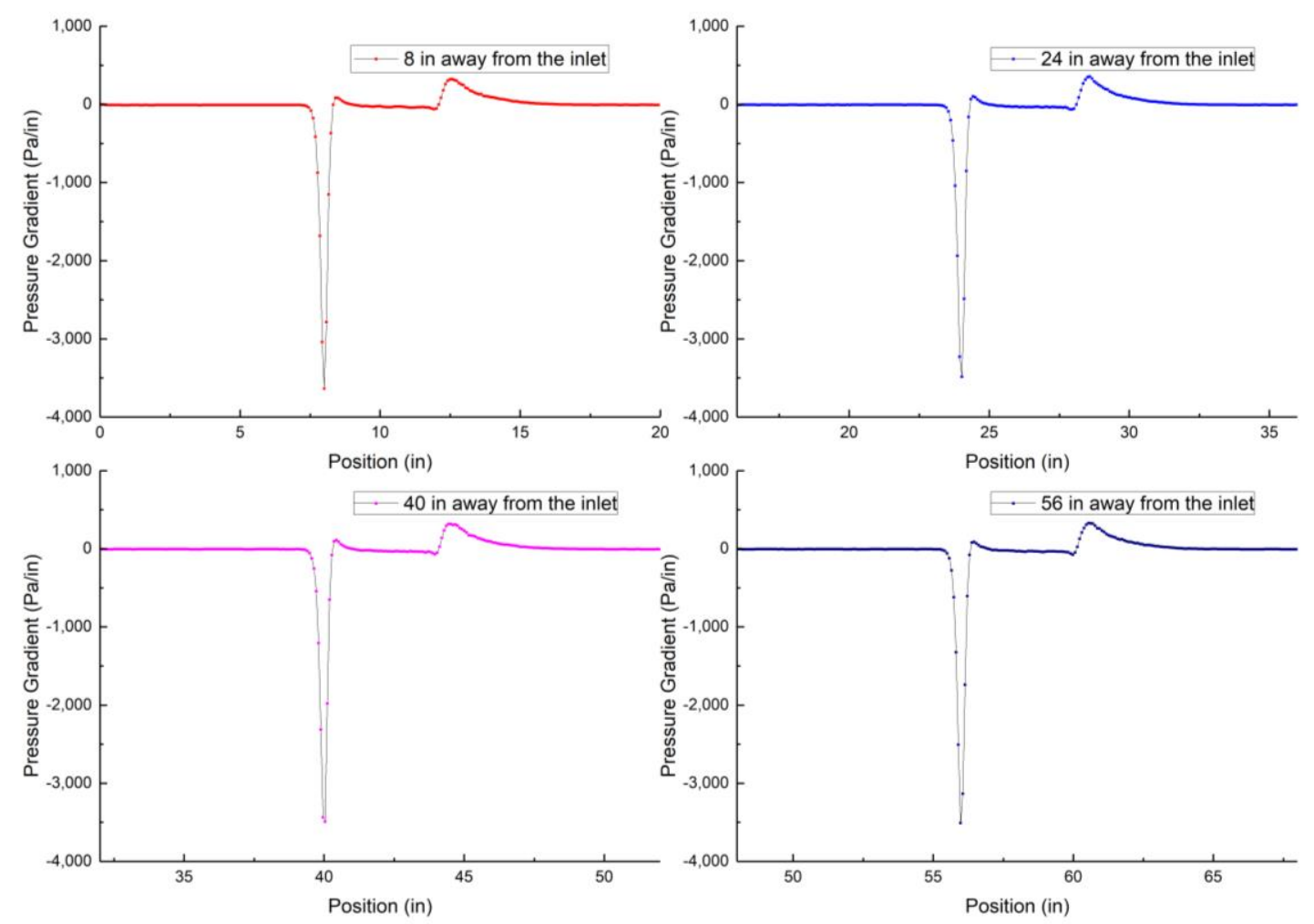

Figure 3.2 Zoom in pressure gradient distribution through blockage in various locations 


\subsubsection{Effect of blockage diameter in vicinity of the blockage}

A systematic study has been carried out using the 3D steady CFD model to investigate the effect of the blockage diameter on the pressure distribution along the whole pipeline. The inner diameters of blockage are taken as $0.24 \mathrm{in}, 0.34$ in and 0.5 in while the rest parameters shown in Table 2.1 keep same in comparing cases.

As can be seen in Figure 3.3, the relative pressure variations for different inner diameters are increasing along with the decrease of diameter. Since the flow area is becoming smaller, it is expected that the pressure drop will be affected due to the increase of pressure loss. On the other hand, based on the observation obtained from the Figure 3.4, the pressure gradient distributions through pipeline blockage are clear and they become more pronounced as the blockage diameter is increased. Especially the pressure gradient varies between $-2 \times 10^{5}$ to around $5 \times 10^{4} \mathrm{~Pa} / \mathrm{in}$ in vicinity of $0.24 \mathrm{in}$. blockage diameter.

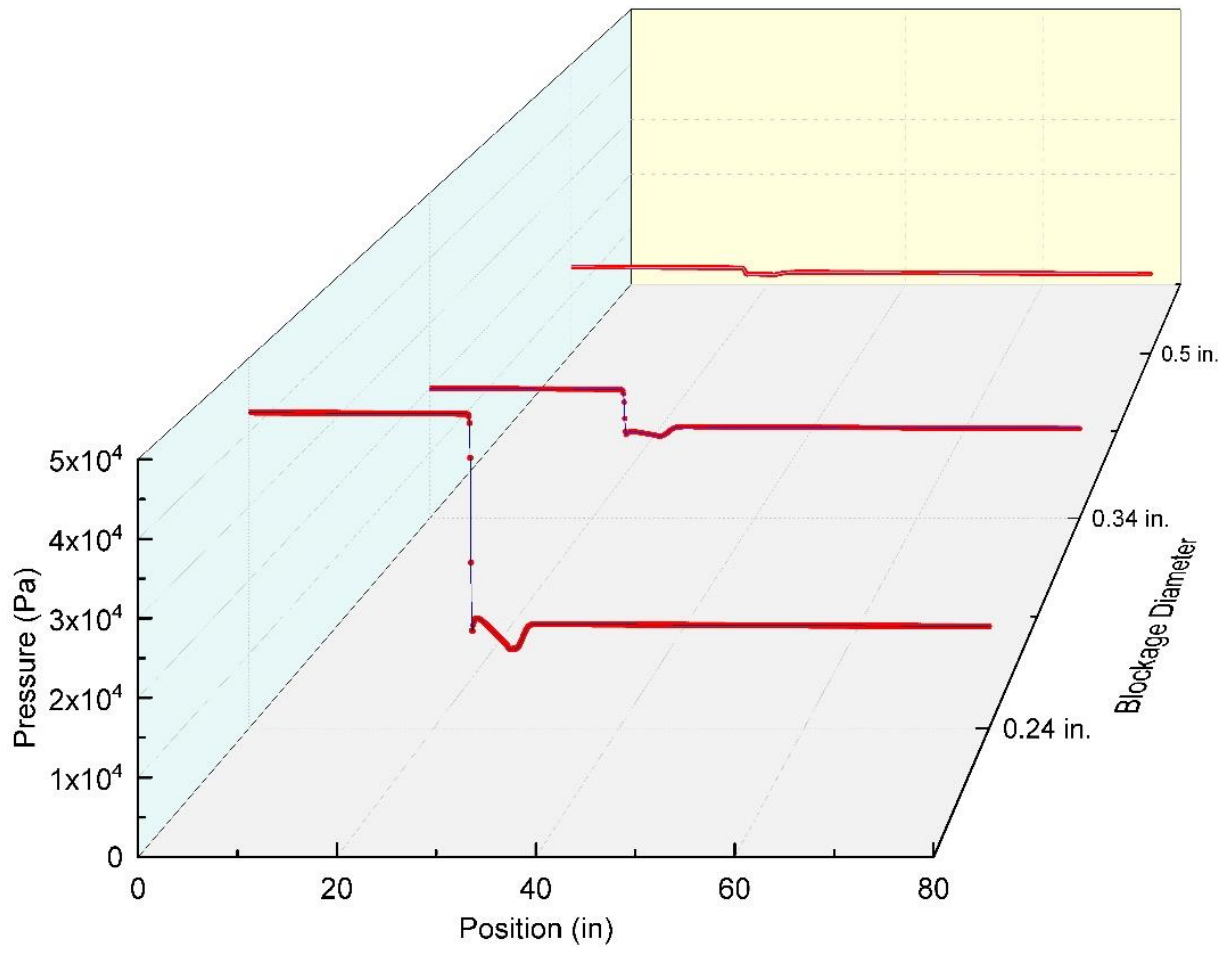

Figure 3.3 Pressure distribution through the pipeline with blockage in various inner diameters 


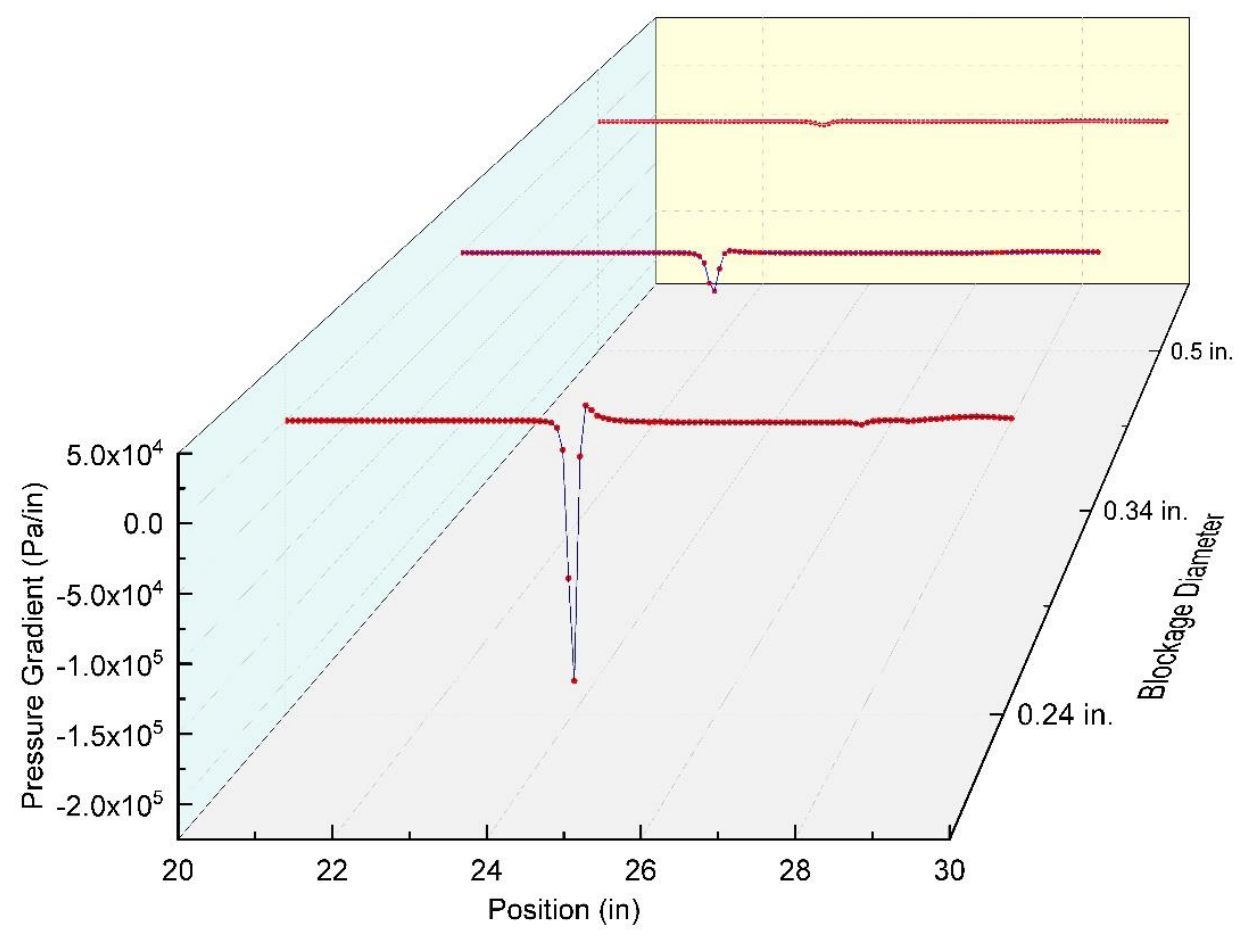

Figure 3.4 Zoom in pressure gradient distribution through blockage in various inner diameters

\subsubsection{Effect of blockage length in vicinity of the blockage}

To analyze the effect of blockage length on the pressure distribution through the pipeline, six different blockage lengths, 0.8 in., 2.4 in., 4 in., 8 in., 16 in. and 40 in., are chosen in the CFD simulations while leaving other parameters same as those in Table 2.1. Figure 3.5 illustrates the simulation results. It can be seen that the longer the blockage length, the larger pressure drop required for the water to reach the pipe outlet. When it comes to the pressure gradient shown in Figure 3.6, the profiles of pressure gradient distribution through pipe centerlines are similar expect that the small variations caused by the different blockage lengths. The maximum changes are located at the blockage inlet section which is about $-3600 \mathrm{~Pa} / \mathrm{in}$. Hence considering a high-efficient blockage detection method, then it is possible to avoid the pipe erosion caused by pressure gradient variations. 

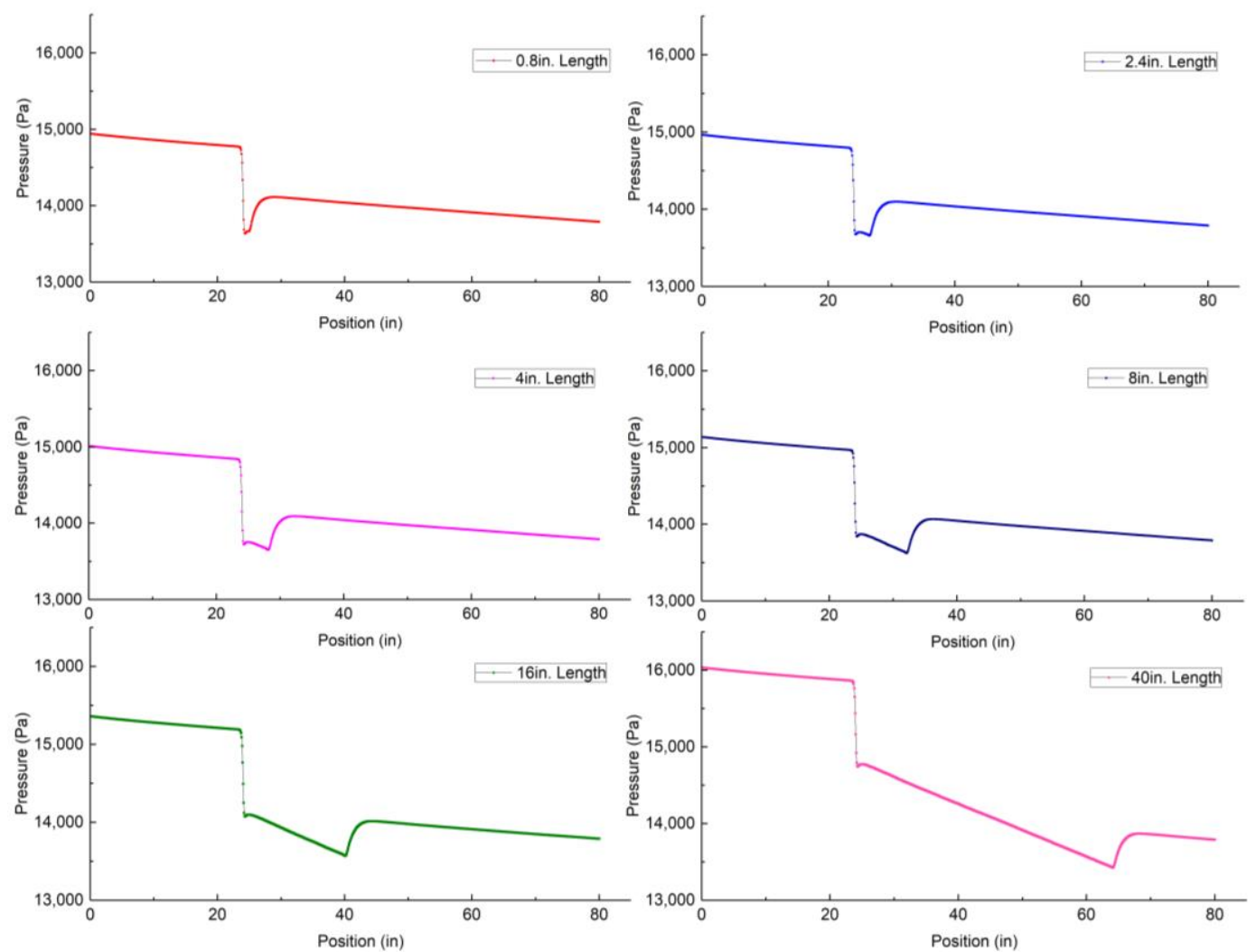

Figure 3.5 Pressure distribution through the pipeline with various blockage lengths
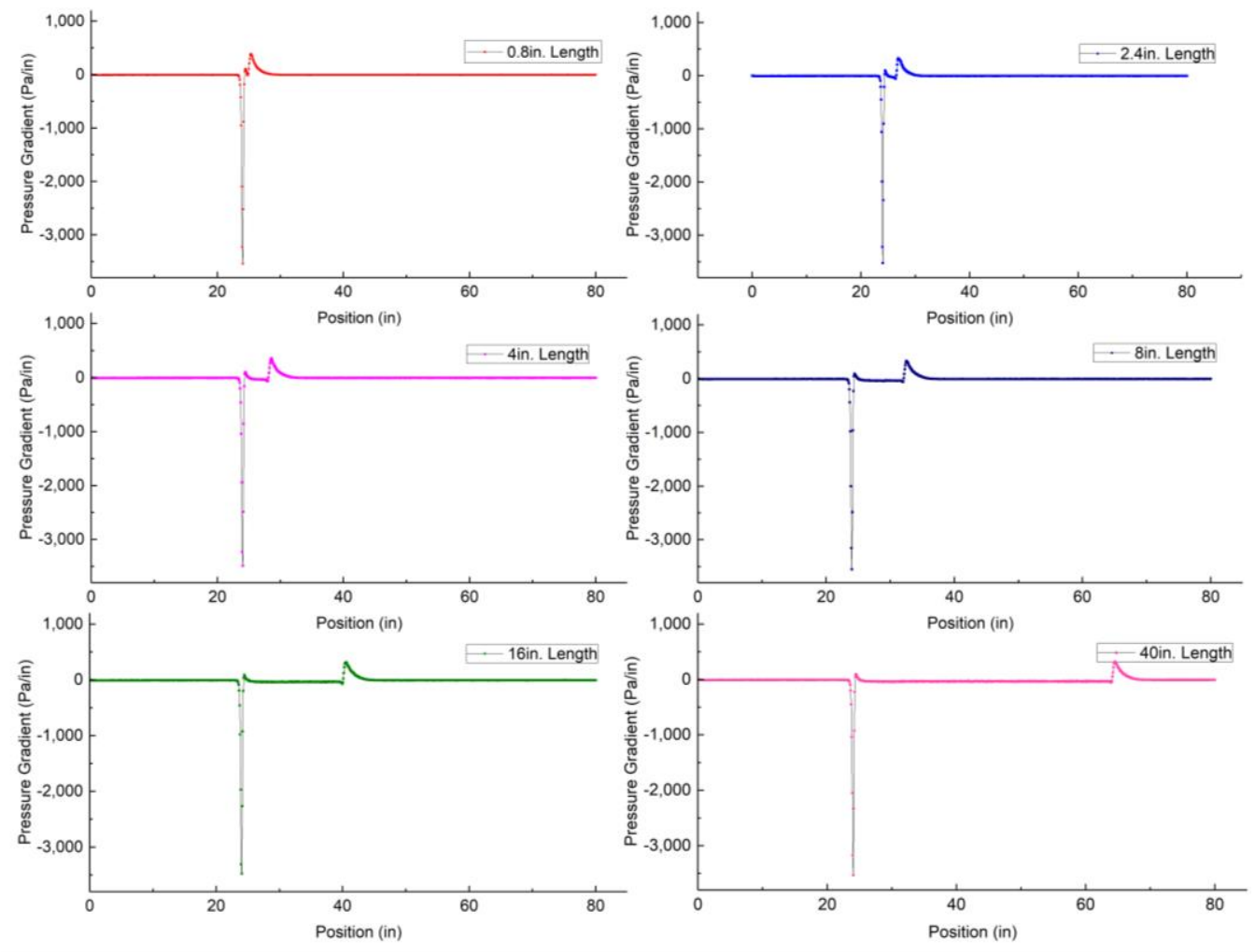

Figure 3.6 Pressure gradient distribution through various blockage lengths 


\subsection{OAT (Orthogonal Array Testing) Technique}

To the best of our knowledge, blockage location, blockage ID and blockage length are generally considered to be the main factors that influence the pressure drop through whole pipeline. Therefore, an orthogonal experiment $\mathrm{L}_{9}(3)^{4}$ was applied to study the extent to which factor affects the pressure drop most. The investigation levels of each factors were selected depending on the above simulation results of single-factor. Table 3.1 lists the independent factors with three variation levels.

Table 3.1 Factors and levels for the orthogonal test

\begin{tabular}{|c|c|c|c|}
\hline No. & (A) Blockage Location/in & (B) Blockage ID/in & (C) Blockage Length/in \\
\hline 1 & 8 & $1 / 2$ & 0.8 \\
\hline 2 & 24 & 0.34 & 4 \\
\hline 3 & 56 & 0.24 & 16 \\
\hline
\end{tabular}

The simulation results of orthogonal test, performed by statistical software Minitab 16.0, are present in Table 3.2. The pressure drop obtained from each test was pretreated and quantitatively analyzed. In view of the orthogonal analysis, we use statistical software to calculate the values of $\mathrm{k}$ and delta. The factors influence the pressure drop through the pipeline with a blockage were listed in a decreasing order as follow: $\mathrm{B}>\mathrm{C}>\mathrm{A}$ according to the delta value. So the maximum pressure drop was obtained when blockage ID, length and location were $\mathrm{B}_{3} \mathrm{C}_{3} \mathrm{~A}_{1}$ (ID 0.24 in., 16 in. length and 8 in. away from the pipe inlet, respectively). According to the delta value, we can find the blockage ID was found to be the most important determinant of the pressure drop through the pipeline.

Table 3.2 Analysis of $L_{9}(3)^{4}$ test results

\begin{tabular}{|c|c|c|c|c|}
\hline No. & (A) Blockage Location/in & (B) Blockage ID/in & (C) Blockage Length/in & Pressure Drop/Pa \\
\hline 1 & 1 & 1 & 1 & 1157.3 \\
\hline 2 & 1 & 2 & 2 & 6318.8 \\
\hline
\end{tabular}




\begin{tabular}{|c|c|c|c|c|}
\hline 3 & 1 & 3 & 3 & 42808.1 \\
\hline 4 & 2 & 1 & 2 & 1221.5 \\
\hline 5 & 2 & 2 & 3 & 8810.6 \\
\hline 6 & 2 & 3 & 1 & 25276.8 \\
\hline 7 & 3 & 2 & 2 & 1564.0 \\
\hline 8 & 3 & 3 & 10691 & 5640.2 \\
\hline 9 & 16761 & 1314 & 12190 & \\
\hline $\mathrm{k} 1$ & 11770 & 6923 & 17728 & \\
\hline $\mathrm{k} 2$ & 12078 & 32372 & 7036 & \\
\hline $\mathrm{k} 3$ & 4992 & 31058 & 2 & \\
\hline Delta & 3 & 1 & & \\
\hline Rank & & & & \\
\hline
\end{tabular}

\subsection{Dimensionless Analysis for Blockage Prediction}

\subsubsection{Dimensionless parameters}

In order to propose a prediction model for locating and estimating the pipeline blockage, several dimensionless parameters whose domains are from 0 to 1 are introduced as follow:

(1) Dimensionless pressure drop:

$$
P_{D}=\frac{\Delta p^{\prime}}{\Delta p}
$$

where $P_{D}$ is the dimensionless pressure drop, $\Delta p^{\prime}$ and $\Delta p$ are the pressure drop through the pipeline with and without blockage, respectively.

(2) Dimensionless blockage location:

$$
E_{D}=\frac{L_{\text {location }}}{L}
$$

where $E_{D}$ is the dimensionless blockage location, $L_{\text {location }}$ is the length between the pipeline inlet and the blockage inlet, and $L$ is the total length of pipeline. 
(3) Dimensionless blockage diameter:

$$
D_{D}=\frac{D^{\prime}}{D}
$$

where $D_{D}$ is the dimensionless blockage diameter, $D^{\prime}$ and $D$ are the inner diameter of the blockage and pipeline, respectively.

(4) Dimensionless blockage length: the ratio of blockage length to the total length of pipeline.

$$
L_{D}=\frac{L^{\prime}}{L}
$$

where $L_{D}$ is the dimensionless pressure length, $L^{\prime}$ and $L$ are the length of the blockage and the pipeline, respectively.

\subsubsection{Blockage Dimensionless analysis}

Plot dimensionless curves based on data obtained in CFD simulation results as above and the fitting curves are obtained as shown in Figure 3.7.

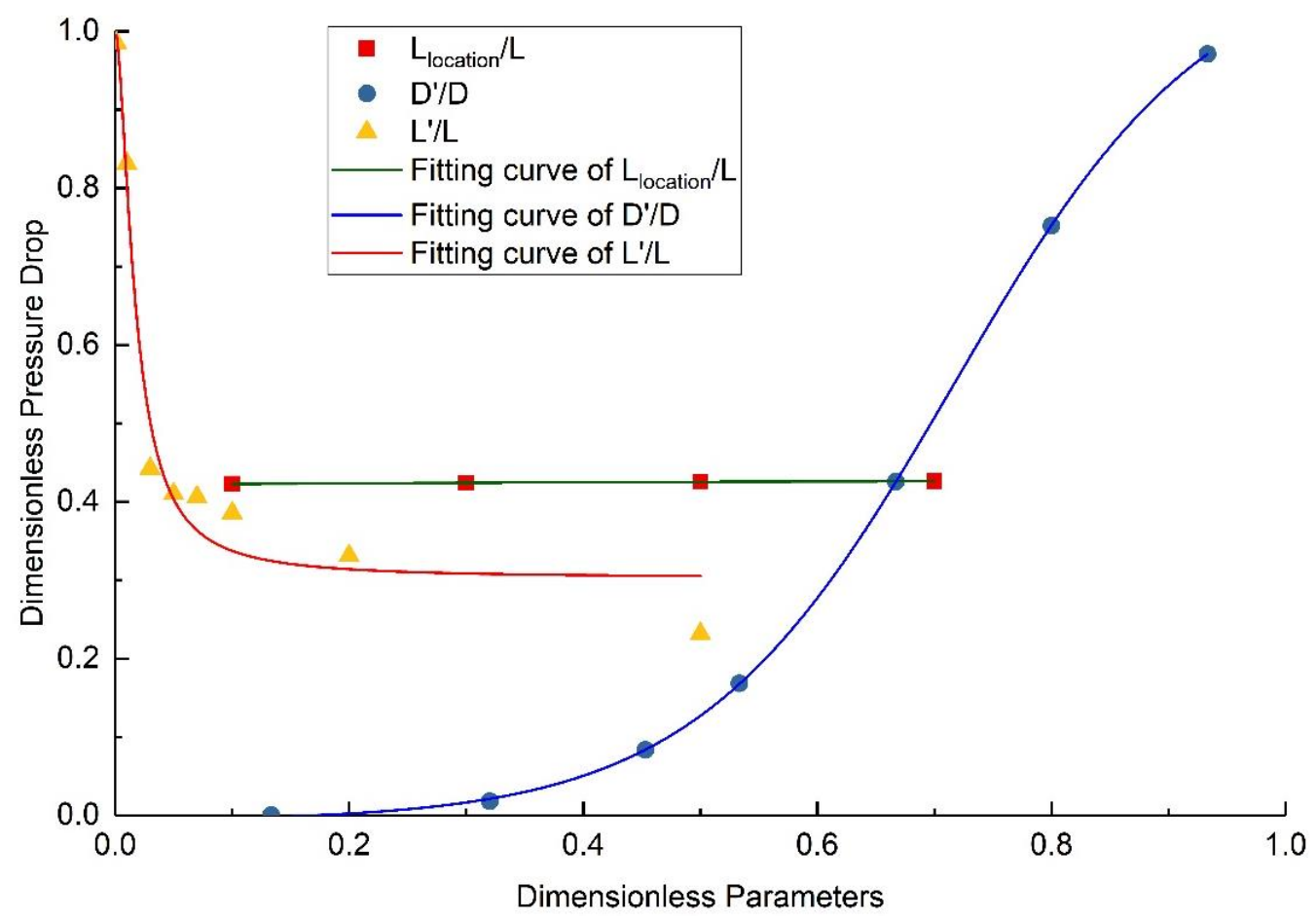

Figure 3.7 Dimensionless pressure drop through pipeline under various parameters 
The $\mathrm{x}$-axis is dimensionless parameters including dimensionless blockage location, dimensionless blockage diameter and dimensionless blockage length whose ranges are all from 0 to 1 . The y-axis is dimensionless pressure drop through the pipeline. We can clearly see that the smaller diameter of the pipeline blockage is, or the longer lengths of the pipeline blockage, the smaller dimensionless pressure drop is. According to their fitting curves, the blockage distribution model is proposed and is shown in Figure 3.8.

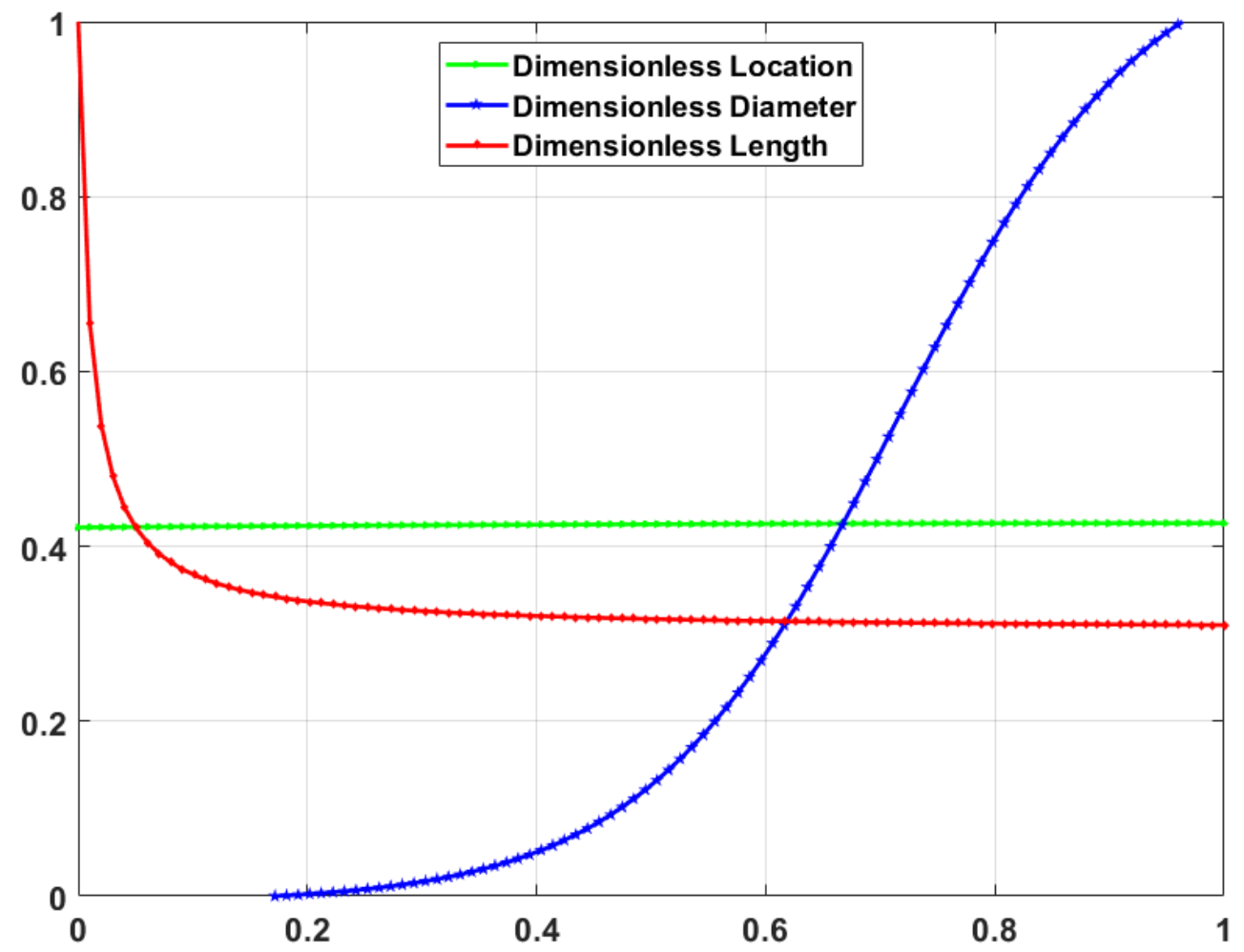

Figure 3.8 Blockage estimation figure based on dimensionless analysis

Based on the fitting curves, the dimensionless location, diameter and length meet the exponential distribution, sigmoidal growth and cross distribution well, respectively. And the adjust R-squares are all larger than 0.985. The fitting formulas are shown as follows: 


$$
\begin{aligned}
& \frac{\Delta p}{\Delta p^{\prime}}=\exp \left[-0.86362+0.02381 \times \frac{L_{\text {location }}}{L}-0.01248 \times\left(\frac{L_{\text {location }}}{L}\right)^{2}\right] \\
& \frac{\Delta p}{\Delta p^{\prime}}=-0.00738+\frac{1.1112}{1+10^{3.98939 \times\left(0.71599-\frac{D^{\prime}}{D}\right)}} \\
& \frac{\Delta p}{\Delta p^{\prime}}=0.30286+\frac{0.69803}{1+\left(57.53314 \times \frac{L^{\prime}}{L}\right)^{1.69042}}
\end{aligned}
$$

Therefore, the estimation of blockage location, diameter and length could be obtained based on this prediction model. Taking Eq. (12) for example, if the normal pressure drop is set as $13,000 \mathrm{~Pa}$, the test pressure drop is $30,000 \mathrm{~Pa}$, and the length of pipeline is set as 10,000 in, so the estimated location would be calculated as 4500 in. away from the pipeline inlet. 


\section{CHAPTER IV}

\section{BLOCKAGE PREDICTION MODEL VALIDATION}

\subsection{Laboratory Experiment Set-up}

\subsubsection{Equipment introduction}

The experimental apparatus for laboratory investigation is a fluid frictional loop that shown in Figure 4.1, manufactured by TecQuipment Ltd, which could be used to measure the pressure losses for fluid flow in a wide variety of pipes and fittings. The equipment has three color coded circuits each fitted with valves, pipes, and pipe system components. These allow technicians to examine and compare the different flow, flow measurement techniques and pressure losses. A vertical panel holds all the parts for easy use. To measure pressure loss across components, technicians use differential pressure gauges.

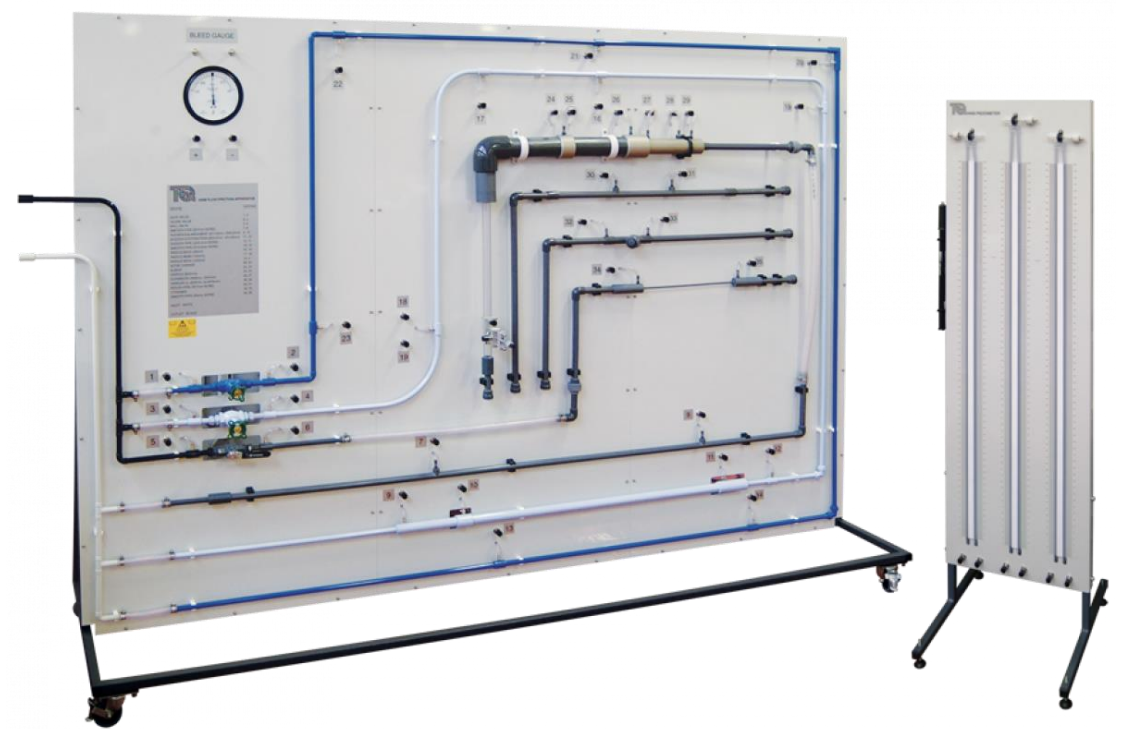

Figure 4.1 The Fluid friction apparatus 
TecQuipment recommends that a hydraulic bench which is used for the circuits with a controlled water supply and flow measurement. The TecQuipment H1D volumetric hydraulic bench is shown in Figure 4.2. To perform experiments, technicians record the temperature of fluid in the hydraulic bench and set the flow rate. They measure pressure losses across instruments or components. These parameters determine the relationship between the flow rate and pressure differential.

The experimental setup will be modified for blockage experiment.

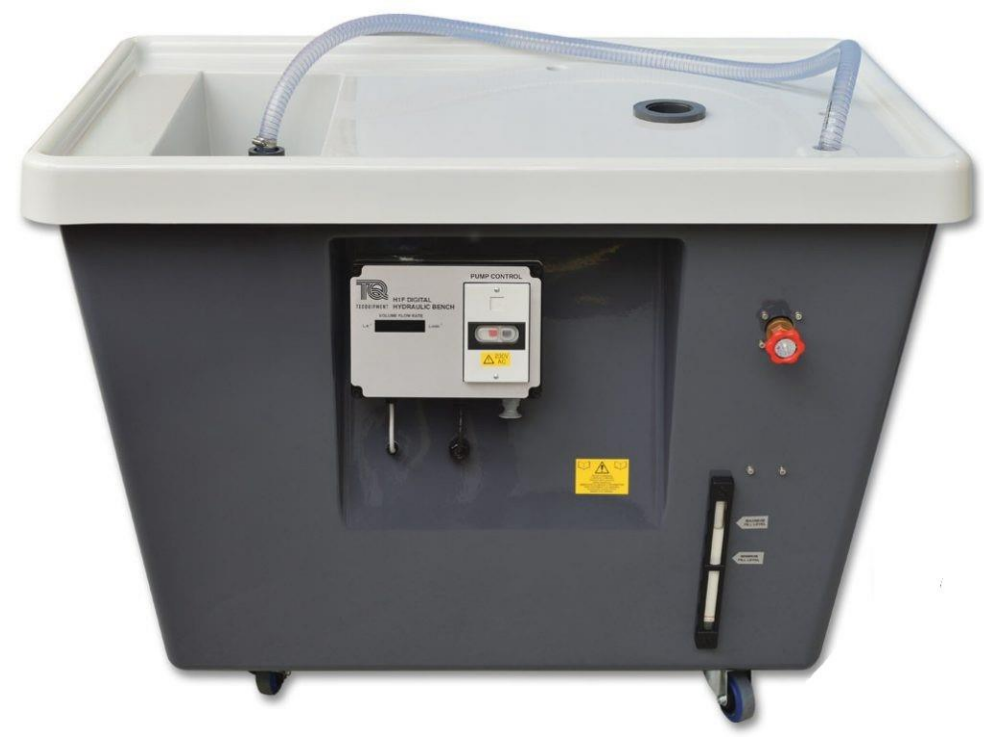

Figure 4.2 The H1D volumetric hydraulic bench

\subsubsection{Equipment modification for blockage experiment}

To investigate the relationship between the blockage characterizations (like blockage location, diameter and length) and the pressure drop through the whole pipe, this fluid frictional apparatus is modified by replacing part of the pipe with a section of smalldiameter pipe (red part blockage section), which simulates the actual partial blockade pipeline. As shown in Figure 4.3, this new apparatus includes the flow sensor connected with the hydraulic bench, the pipe section at the bottom part of this vertical loop connected 
with pressure transmitters, and the data logging system used for recording pressure and the flow rate, automatically.

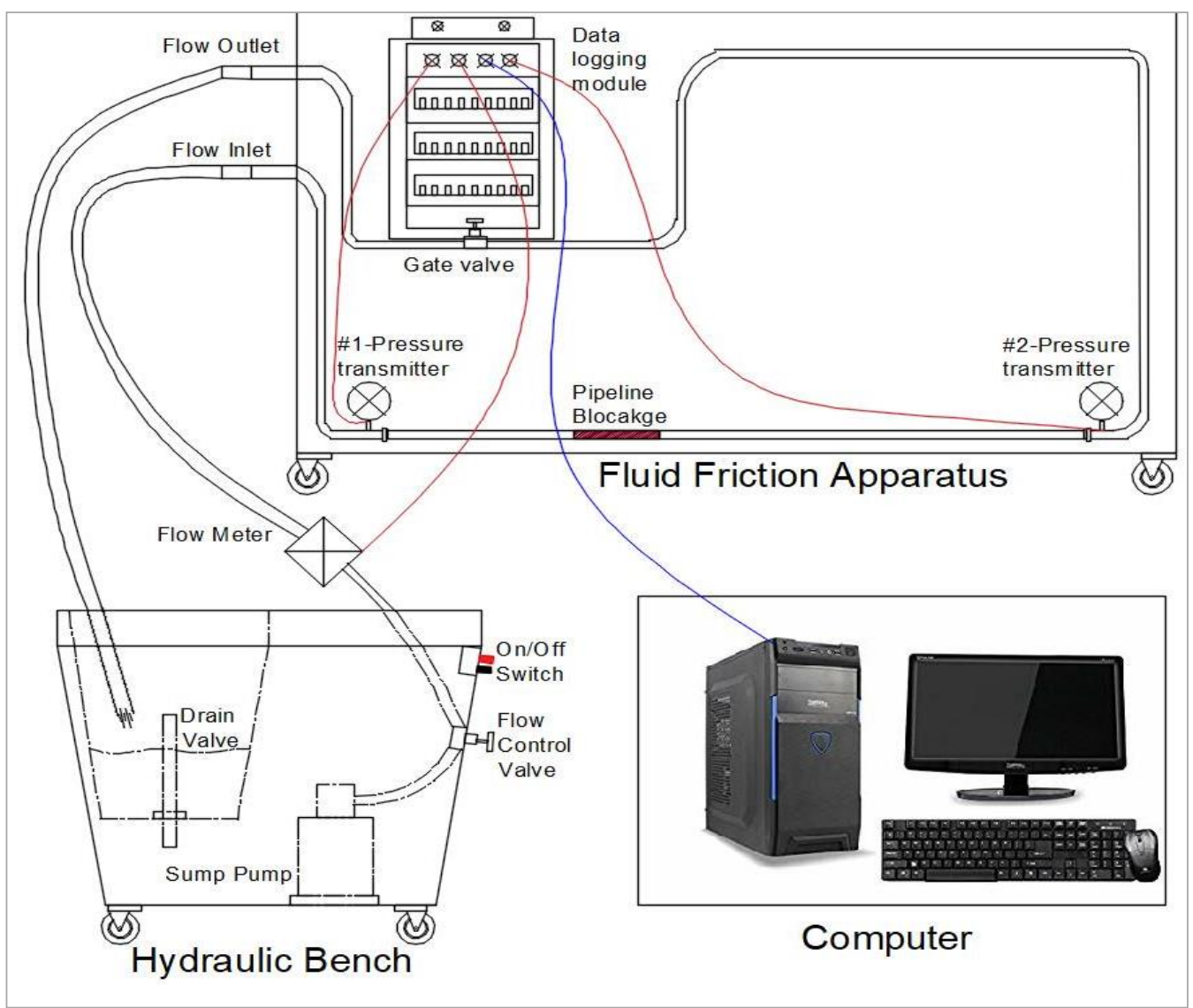

Figure 4.3 Experimental setup for pipeline blockage investigation

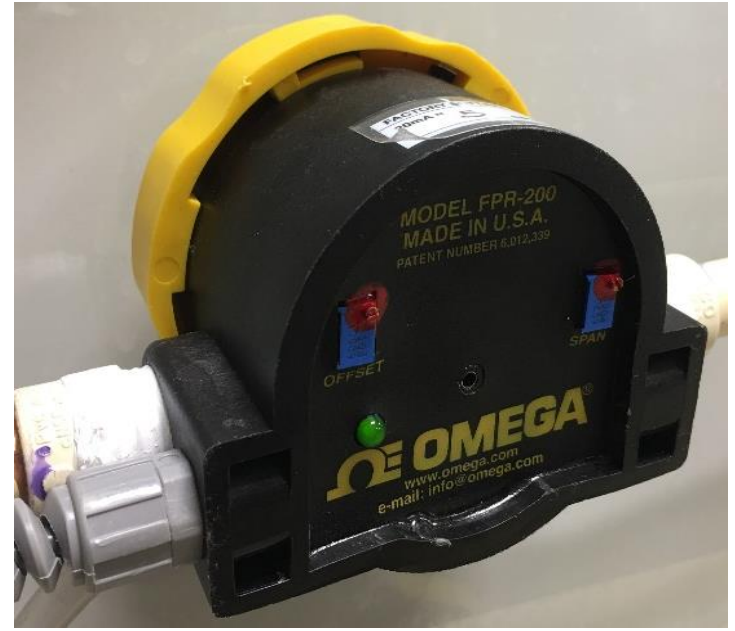

(a)

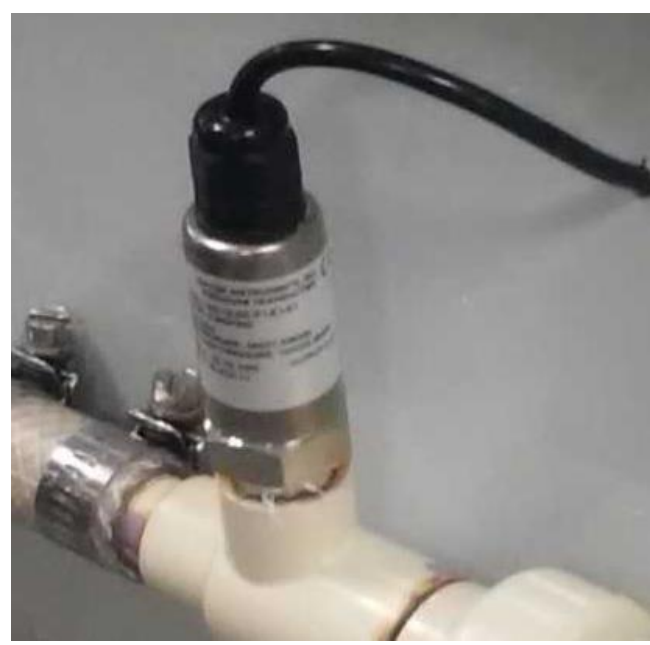

(b)

Figure 4.4 The Instruments used for the blockage experiments 
A flow sensor (shown in Figure 4.4 (a)), manufactured by Omega Company, is deployed to measure flow rates in water circuits by integrating rugged tangential turbine technology with a precision digital to analog conversion circuit hermetically encapsulated within the body of the sensor. The pressure transmitters (\#1, \#2, shown in Figure 4.4 (b)), are installed to convert a single positive pressure into a standard 4-20 mA output signal, which could be recorded by the data logging module.

The data logging system (shown in Figure 4.5) which consists of the chassis and module from National Instruments is set up to record the pressure point and the flow rate change while running experiments. The chassis is mounted on the back of the vertical panel board and the corresponding modules are inserted. Wirings are also used to connect the pressure transmitters and the flow rate sensor to the appropriate ports in the module. On the other hand, the chassis is connected to the computer by wirings. For the data logging system, it should be programmed for required drivers by the LabVIEW software. The final screen shot of the data logging system is shown in Figure 4.6 and it is set to record the pressure signal and the flow rate signal per 0.5 second. And in this software, it is clearly to check the value of inlet or outlet pressure and the flow rate.

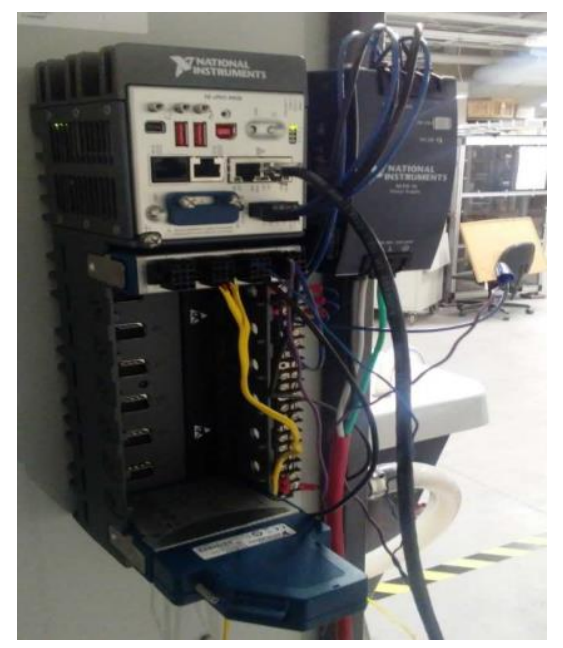

Figure 4.5 The Data logging system used for the blockage experiments 


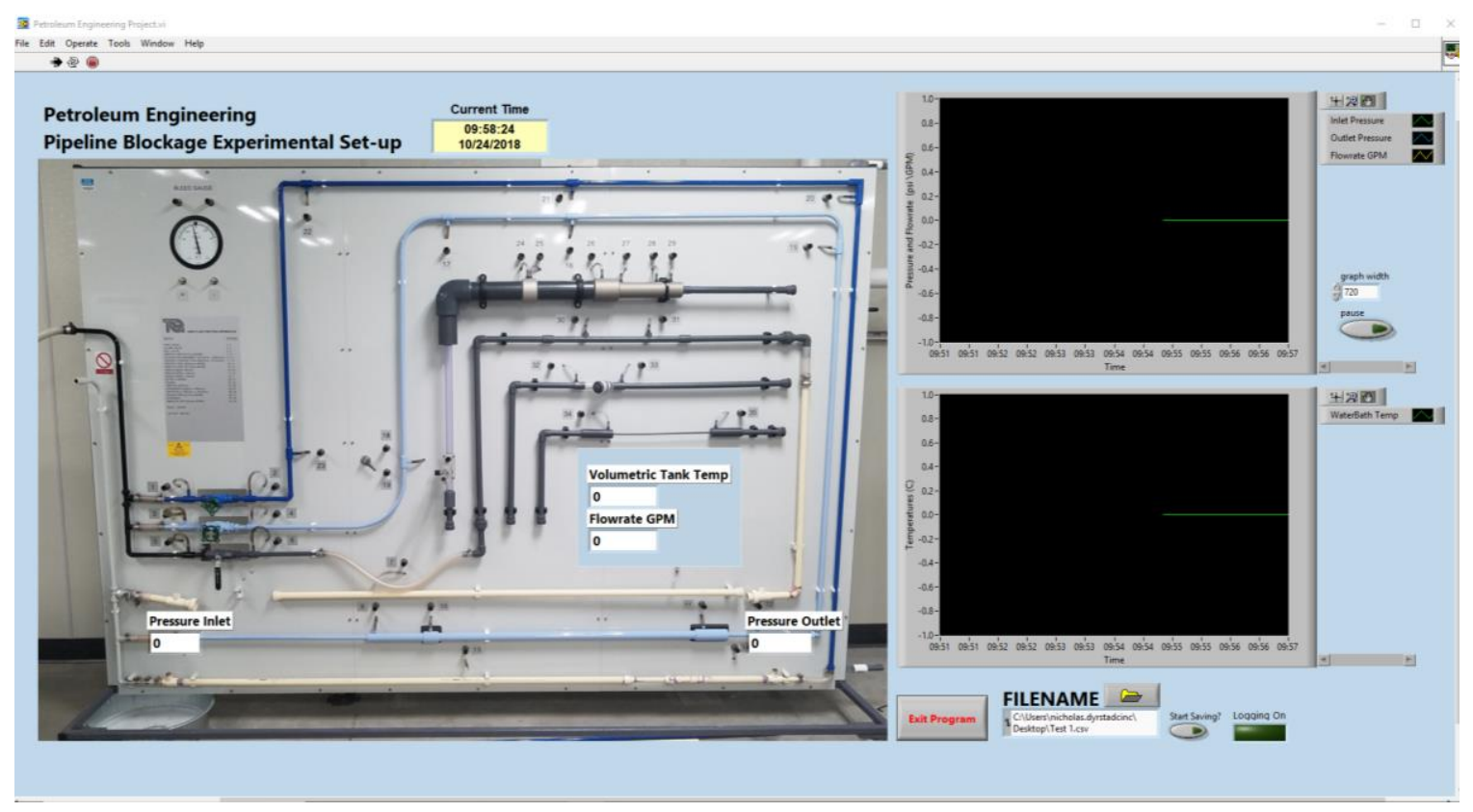

Figure 4.6 LabVIEW Software used for pipeline blockage experiment

To investigate the blockage experiment, part of the pipe at the bottom of this apparatus is replaced with a smaller-diameter pipe section to simulate the actual blockage. The location of the smaller-diameter pipe section will be changed to simulate different locations of blockage pipeline. Next, part of pipe sections with the same length but different diameter will be replaced to study how blockage diameter influences the distribution of the pressure. Finally, part of pipe sections with the same diameter but different lengths will be used to study the blockage length effects on the pressure drop through the pipeline.

\subsection{Experiment Investigation}

\subsubsection{Standard cases}

Standard cases include the pipeline without blockage and the pipeline with a single blockage. The modified apparatus is used to run the first experiment while the pipe at the bottom of this apparatus is replaced to a CPVC pipe with $3 / 4$ in. diameter simulated as the whole pipe without blockage. In order to obtain the pressure drop through the pipeline, the 
difference between the values shown on the LabVIEW software which obtained from these two pressure transmitters are taken as the pressure drop through the pipeline. Steps to investigate the single blockage experiments are similar to the first one while part of bottom pipe is replaced with a 0.5 in-diameter pipe section to simulate the blockage. The detail of the experiment parameters is shown in Table 4.1 .

Table 4.1 Experiment parameters for standard cases

\begin{tabular}{|c|c|c|c|c|c|}
\hline Case & $\begin{array}{c}\text { Pipe } \\
\text { Diameter/in. }\end{array}$ & $\begin{array}{c}\text { Pipe } \\
\text { Length/in. }\end{array}$ & $\begin{array}{c}\text { Blockage } \\
\text { Diameter/in. }\end{array}$ & $\begin{array}{c}\text { Blockage } \\
\text { Length/in. }\end{array}$ & $\begin{array}{c}\text { Blockage Location/in. } \\
\text { away from the pipe inlet }\end{array}$ \\
\hline 1 & $3 / 4$ & 80 & -- & -- & -- \\
\hline 2 & $3 / 4$ & 80 & 0.5 & 8 & 22 \\
\hline
\end{tabular}

\subsubsection{Experiments for single blockage at different locations}

Steps to conduct blockage experiments at various locations are similar to the standard case with single blockage. The only difference is different locations of the blockage are installed. Multiple flow rate tests are run and pressure parameters are recorded for all different cases. The detail of the experiment parameters is shown in Table 4.2.

Table 4.2 Experiment parameters for single blockage at different locations

\begin{tabular}{|c|c|c|c|c|c|}
\hline Case & $\begin{array}{c}\text { Pipe } \\
\text { Diameter/in. }\end{array}$ & $\begin{array}{c}\text { Pipe } \\
\text { Length/in. }\end{array}$ & $\begin{array}{c}\text { Blockage } \\
\text { Diameter/in. }\end{array}$ & $\begin{array}{c}\text { Blockage } \\
\text { Length/in. }\end{array}$ & $\begin{array}{c}\text { Blockage Location/in. } \\
\text { away from the pipe inlet }\end{array}$ \\
\hline 1 & $3 / 4$ & 80 & 0.5 & 8 & 15 \\
\hline 2 & $3 / 4$ & 80 & 0.5 & 8 & 22 \\
\hline 3 & $3 / 4$ & 80 & 0.5 & 8 & 37 \\
\hline 4 & $3 / 4$ & 80 & 0.5 & 8 & 50 \\
\hline 5 & $3 / 4$ & 80 & 0.5 & 8 & 58 \\
\hline 6 & $3 / 4$ & 80 & 0.5 & 8 & \\
\hline
\end{tabular}

\subsubsection{Experiments for single blockage with different diameters}

To investigate the influence of blockage diameter on the pressure drop though the pipeline, the simulated part of blockage section is replaced with various diameters while 
keeping the rest parameters same. The details of the experiment parameters are shown in Table 4.3.

Table 4.3 Experiment parameters for single blockage with different diameters

\begin{tabular}{|c|c|c|c|c|c|}
\hline Case & $\begin{array}{c}\text { Pipe } \\
\text { Diameter/in. }\end{array}$ & $\begin{array}{c}\text { Pipe } \\
\text { Length/in. }\end{array}$ & $\begin{array}{c}\text { Blockage } \\
\text { Diameter/in. }\end{array}$ & $\begin{array}{c}\text { Blockage } \\
\text { Length/in. }\end{array}$ & $\begin{array}{c}\text { Blockage Location/in. } \\
\text { away from the pipe inlet }\end{array}$ \\
\hline 1 & $3 / 4$ & 80 & 0.5 & 8 & 15 \\
\hline 2 & $3 / 4$ & 80 & 0.34 & 8 & 15 \\
\hline 3 & $3 / 4$ & 80 & 0.24 & 8 & 50 \\
\hline 4 & $3 / 4$ & 80 & 0.5 & 8 & 50 \\
\hline 5 & $3 / 4$ & 80 & 0.34 & 8 & 50 \\
\hline 6 & $3 / 4$ & 80 & 0.24 & 8 & 15 \\
\hline
\end{tabular}

\subsubsection{Experiments for single blockage with different lengths}

Steps to conduct blockage experiments with different lengths are similar to the Section 4.2.2 while replacing the blockage section with different lengths of pipe sections. Multiple flow rate tests are investigated and pressure parameters are recorded for all different cases. The detail of the experiment parameters is shown in Table 4.4.

Table 4.4 Experiment parameters for single blockage with different lengths

\begin{tabular}{|c|c|c|c|c|c|}
\hline Case & $\begin{array}{c}\text { Pipe } \\
\text { Diameter/in. }\end{array}$ & $\begin{array}{c}\text { Pipe } \\
\text { Length/in. }\end{array}$ & $\begin{array}{c}\text { Blockage } \\
\text { Diameter/in. }\end{array}$ & $\begin{array}{c}\text { Blockage } \\
\text { Length/in. }\end{array}$ & $\begin{array}{c}\text { Blockage Location/in. } \\
\text { away from the pipe inlet }\end{array}$ \\
\hline 1 & $3 / 4$ & 80 & 0.5 & 4 & 23 \\
\hline 2 & $3 / 4$ & 80 & 0.5 & 8 & 23 \\
\hline 3 & $3 / 4$ & 80 & 0.5 & 40 & 4 \\
\hline 4 & $3 / 4$ & 80 & 0.5 & 72 & 20 \\
\hline
\end{tabular}

\subsection{Experiment Results and Discussion}

In order to validate the blockage prediction model based on CFD simulation results, the flow rate was kept as same as the CFD boundary situation and is set to 2.7 GPM in the lab experiments. The experiment results are shown in Table 4.5 by following the steps of 
blockage experiment described in Chapter 4.2. To conveniently present the differences between the experiment results and the prediction results, the corresponding dimensionless parameters are calculated followed by the equations shown in Chapter 3.3 and are list in Table 4.6. The obtained deviations of pressure drop between the experiment results and the prediction results show, in a clear way, the experiment results are larger than the prediction results. The deviations of pressure drop through the pipeline under different locations vary from $7 \%$ to $22 \%$. The deviations of pressure drop with different diameters vary from $10 \%$ to $30 \%$. And the deviations of pressure drop vary from $2 \%$ to $22 \%$. Hence the deviation should be taken into account while estimating the blockage through the pipeline based on the blockage prediction model. 
Table 4.5 Blockage experiment results

\begin{tabular}{|c|c|c|c|c|c|c|}
\hline Case & Pipe Diameter/in. & Pipe Length/in. & Blockage Diameter/in. & Blockage Length/in. & Blockage Location/in. & Pressure Drop/Pa \\
\hline NO Blockage & $3 / 4$ & 80 & -- & -- & -- & 2600 \\
\hline Standard Case & $3 / 4$ & 80 & 0.5 & 8 & 22 & 5250 \\
\hline \multicolumn{7}{|c|}{ Different Locations } \\
\hline 1 & $3 / 4$ & 80 & 0.5 & 8 & 15 & 5300 \\
\hline 2 & $3 / 4$ & 80 & 0.5 & 8 & 22 & 5240 \\
\hline 3 & $3 / 4$ & 80 & 0.5 & 8 & 35 & 4970 \\
\hline 4 & $3 / 4$ & 80 & 0.5 & 8 & 37 & 4720 \\
\hline 5 & $3 / 4$ & 80 & 0.5 & 8 & 50 & 5710 \\
\hline 6 & $3 / 4$ & 80 & 0.5 & 8 & 58 & 4860 \\
\hline \multicolumn{7}{|c|}{ Different Diameters } \\
\hline 1 & $3 / 4$ & 80 & 0.5 & 8 & 15 & 5340 \\
\hline 2 & $3 / 4$ & 80 & 0.34 & 8 & 15 & 17490 \\
\hline 3 & $3 / 4$ & 80 & 0.24 & 8 & 15 & 51200 \\
\hline 4 & $3 / 4$ & 80 & 0.5 & 8 & 50 & 4890 \\
\hline 5 & $3 / 4$ & 80 & 0.34 & 8 & 50 & 19340 \\
\hline 6 & $3 / 4$ & 80 & 0.24 & 8 & 50 & 57600 \\
\hline \multicolumn{7}{|c|}{ Different Lengths } \\
\hline 1 & $3 / 4$ & 80 & 0.5 & 4 & 23 & 4910 \\
\hline 2 & $3 / 4$ & 80 & 0.5 & 8 & 23 & 6240 \\
\hline 3 & $3 / 4$ & 80 & 0.5 & 40 & 20 & 7910 \\
\hline 4 & $3 / 4$ & 80 & 0.5 & 72 & 4 & 8450 \\
\hline
\end{tabular}


Table 4.6 Blockage prediction model validation

\begin{tabular}{|c|c|c|c|c|c|c|}
\hline Case & $\begin{array}{c}\text { Dimensionless } \\
\text { Blockage Diameter. }\end{array}$ & $\begin{array}{c}\text { Dimensionless } \\
\text { Blockage Length }\end{array}$ & $\begin{array}{c}\text { Dimensionless } \\
\text { Blockage Location }\end{array}$ & $\begin{array}{c}\text { Dimensionless Pressure } \\
\text { Drop By Experiment }\end{array}$ & $\begin{array}{c}\text { Dimensionless Pressure } \\
\text { Drop By Model }\end{array}$ & Deviation/\% \\
\hline $\begin{array}{c}\text { Standard } \\
\text { Case }\end{array}$ & 0.667 & 0.1 & 0.28 & 0.4961 & 0.4240 & 14.53 \\
\hline \multicolumn{7}{|c|}{ Different Locations } \\
\hline 1 & 0.667 & 0.1 & 0.18 & 0.4905 & 0.4232 & 13.71 \\
\hline 2 & 0.667 & 0.1 & 0.28 & 0.4961 & 0.4240 & 14.53 \\
\hline 3 & 0.667 & 0.1 & 0.44 & 0.5231 & 0.4250 & 18.75 \\
\hline 4 & 0.667 & 0.1 & 0.46 & 0.5508 & 0.4252 & 22.82 \\
\hline 5 & 0.667 & 0.1 & 0.62 & 0.4553 & 0.4258 & 6.47 \\
\hline 6 & 0.667 & 0.1 & 0.72 & 0.5349 & 0.4261 & 20.34 \\
\hline \multicolumn{7}{|c|}{ Different Diameters } \\
\hline 1 & 0.667 & 0.1 & 0.18 & 0.4868 & 0.4392 & 9.79 \\
\hline 2 & 0.453 & 0.1 & 0.18 & 0.1486 & 0.0987 & 33.59 \\
\hline 3 & 0.32 & 0.1 & 0.18 & 0.0507 & 0.0358 & 29.36 \\
\hline 4 & 0.667 & 0.1 & 0.62 & 0.5317 & 0.4392 & 17.4 \\
\hline 5 & 0.453 & 0.1 & 0.62 & 0.1344 & 0.0987 & 26.56 \\
\hline 6 & 0.32 & 0.1 & 0.62 & 0.0451 & 0.0358 & 20.53 \\
\hline \multicolumn{7}{|c|}{ Different Lengths } \\
\hline 1 & 0.667 & 0.05 & 0.28 & 0.5295 & 0.4031 & 23.88 \\
\hline 2 & 0.667 & 0.1 & 0.28 & 0.4167 & 0.3373 & 19.04 \\
\hline 3 & 0.667 & 0.5 & 0.19 & 0.3286 & 0.3052 & 7.14 \\
\hline 4 & 0.667 & 0.9 & 0.04 & 0.3076 & 0.3037 & 1.28 \\
\hline
\end{tabular}




\section{CHAPTER V \\ CONCLUSIONS AND FUTURE WORKS}

\subsection{Conclusions}

CFD simulations, for studying pressure distribution through the pipeline without/with a single blockage are investigated. Effects of lockage location, blockage diameter and blockage length on the pressure drop through the pipeline are examined. And fitting formulas are obtained to estimate the corresponding the location, diameter and length of the pipeline blockage. Finally, a prediction model of the pipeline blockage is proposed and is validated by the corresponding lab experiments. Based on this research, the following conclusions are drawn as:

(1) Pipeline blockage- may result from bad operating conditions or from any reason, due to sudden changes of pressure, temperature, corrosion action, composition or lack of maintenance. Before any detection methods are implemented, it is important to assess what is contributing to the blockage formation.

(2) For blockage detection methods, mathematical method has the privilege to narrow down the possible blockage interval, especially for long-distance pipeline, then physical method is applied to locate blockage accurately and evaluate severity confidently. Attention needs to be taken at this stage to make sure that the detection method itself would not deteriorate the blockage or make it harder to remediate in future work. 
(3) The larger the blockage diameter, the longer the blockage length, or the more far away from the pipe inlet, the larger pressure drop through the pipeline is. Based on the CFD simulations and the OAT analysis, the factors that influence the pressure drop through the pipeline are listed in a decreasing order as blockage diameter, blockage length and blockage location.

(4) The three fitting formulas of dimensionless parameters distribution meet the exponential distribution, sigmoidal growth and cross distribution well, respectively. Using the formulas, we can locate the pipeline blockage and estimate its diameter and length as well.

(5) Laboratory experiments are investigated under different operations to simulate the actual pipeline without/with a single blockage. The experiment results are larger than the results calculated by the proposed prediction model. And the deviation is under $30 \%$ which should be considered while estimating the blockage through the pipeline based on the blockage prediction model.

\subsection{Future Works}

Many mathematical models are available to detect pipeline blockages while their applicability is limited to single blockage in a pipeline, which just covers a small part of pipeline operation circumstances. The future work of detection methods should focus on how to detect the multiple blockages in single/multiphase flow in more complicate pipelines like parallel/looped pipelines. 


\section{NOMENCLATURE}

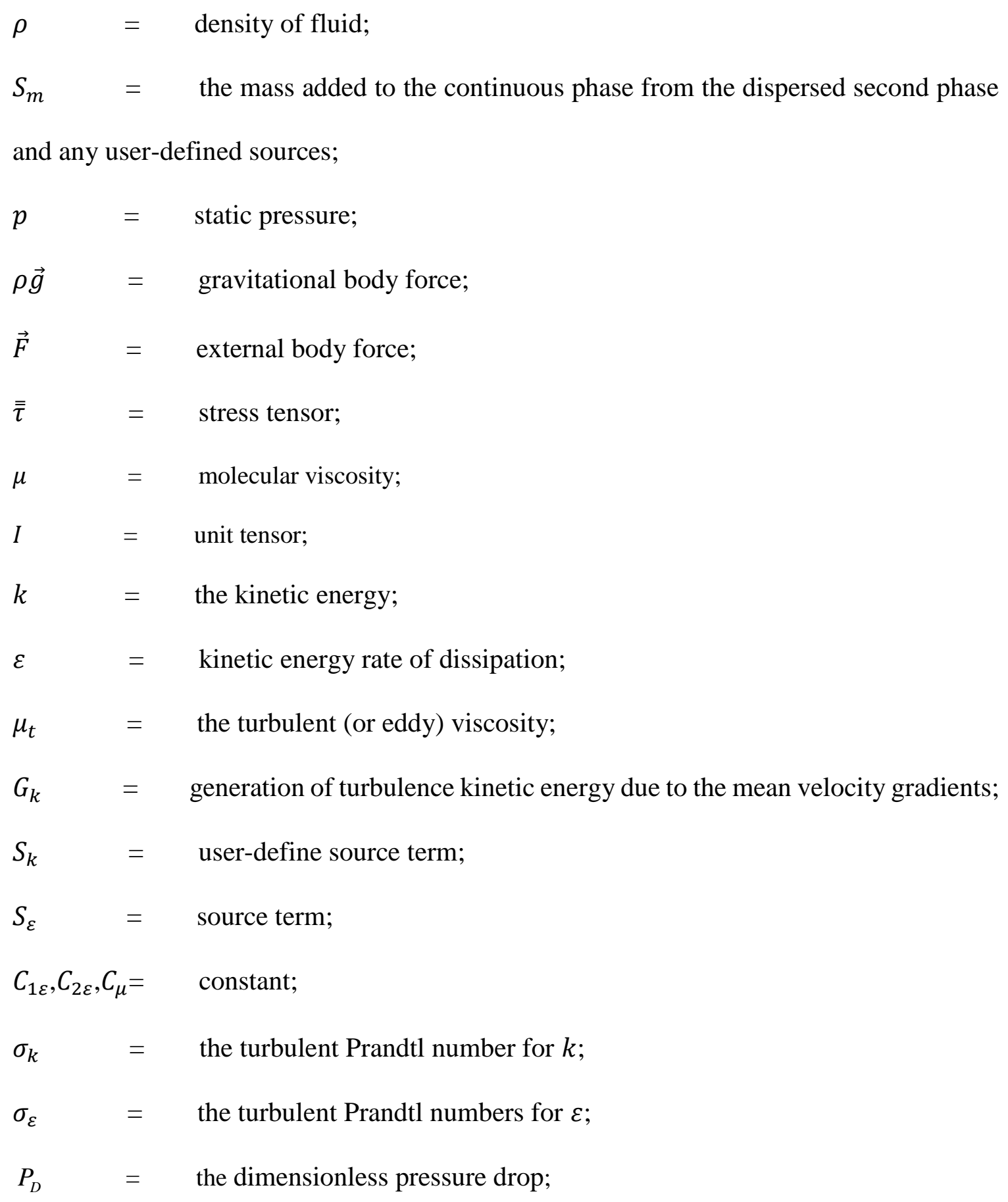




$\begin{array}{lll}\Delta p^{\prime} & = & \text { the pressure drop through the pipeline with blockage; } \\ \Delta p & = & \text { the pressure drop through the pipeline without blockage; } \\ E_{D} & = & \text { the dimensionless blockage location; } \\ L_{\text {location }} & = & \text { the length between the pipeline inlet and the blockage inlet; } \\ L_{D} & = & \text { the total length of pipeline; } \\ D_{D} & = & \text { the dimensionless blockage diameter; } \\ D^{\prime} & = & \text { the inner diameter of the pipeline; } \\ D & = & \text { the dimensionless pressure length; } \\ L_{D} & = & \text { the length of the blockage; } \\ L^{\prime} & =\end{array}$




\section{REFERENCES}

Adeleke, N., Ityokumbul, M. T., \& Adewumi, M. (2012). Blockage detection and characterization in natural gas pipelines by transient pressure-wave reflection analysis. SPE Journal, 18(02), 355-365.

Adewumi, M. A., Eltohami, E. S., \& Solaja, A. (2003). Possible detection of multiple blockages using transients. Journal of energy resources technology, 125(2), 154-159.

Arpino, F., \& Massarotti, N. (2009). Numerical simulation of mass and energy transport phenomena in solid oxide fuel cells. Energy, 34(12), 2033-2041.

Bukkaraju, S. K., Osorio, N. F., Annadorai, K. M., Garduño, J. L., \& Golden, N. K. (2016, May). Practical Guidelines for the Diagnosis and Remediation of Pipeline Blockages. In Offshore Technology Conference. Offshore Technology Conference.

Charlton, J. S., Heslop, J. A., \& Johnson, P. (1982). Radioisotope techniques for the investigation of process problems in the chemical industry. In Industrial application of radioisotopes and radiation technology: proceedings of an International Conference on Industrial Application of Radioisotopes and Radiation Technology (Vol. 598, p. 393). Intl Atomic Energy Agency.

Chen, X., Tsang, Y., Zhang, H. Q., \& Chen, T. X. (2007, January). Pressure-wave propagation technique for blockage detection in subsea flowlines. In SPE Annual Technical Conference and Exhibition. Society of Petroleum Engineers. 
Datta, S., \& Sarkar, S. (2016). A review on different pipeline fault detection methods. Journal of Loss Prevention in the Process Industries, 41, 97-106.

Duan, H. F., Lee, P. J., Ghidaoui, M. S., \& Tung, Y. K. (2011). Extended blockage detection in pipelines by using the system frequency response analysis. Journal of Water Resources Planning and Management, 138(1), 55-62.

Jalilinasrabady, S., Palsson, H., Saevarsdottir, G., Itoi, R., \& Valdimarsson, P. (2013). Experimental and CFD simulation of heat efficiency improvement in geothermal spas. Energy, 56, 124-134.

Kasban, H., Zahran, O., \& El-Samie, F. A. (2010). New trends for on-line troubleshooting in industrial problems using radioisotopes. Journal of Electronics and Electrical Engineering, 2(3), 284-292.

Koyama, H., \& Watanabe, K. (1990). Identification of a Partial Plugging in a GasTransport Pipeline by Acoustic Method. Transactions of the Society of Instrument and Control Engineers, 26(3), 259-265.

Lee, P. J., Vítkovský, J. P., Lambert, M. F., Simpson, A. R., \& Liggett, J. A. (2008). Discrete blockage detection in pipelines using the frequency response diagram: numerical study. Journal of Hydraulic Engineering, 134(5), 658-663.

Liu, L. J., \& Scott, S. L. (2001, January). A new method to locate partial blockages in subsea flowlines. In SPE Annual Technical Conference and Exhibition. Society of Petroleum Engineers. 
Liu, L., \& Scott, S. L. (2000, January). Development of a type curve to locate partial blockages in gas flowlines. In SPE Annual Technical Conference and Exhibition. Society of Petroleum Engineers.

MacIntyre, W. J., Friedell, H. L., Crespo, G. G., \& Rejali, A. M. (1959). The visualization of internal organs by accentuation scintillation scanning technics. Radiology, 73(3), 329340.

Mohapatra, P. K., Chaudhry, M. H., Kassem, A. A., \& Moloo, J. (2006). Detection of partial blockage in single pipelines. Journal of Hydraulic Engineering, 132(2), 200-206.

Parker, J. (1981). Acoustic detection and location of leaks in underground natural gas distribution lines. John Hopkins APL Technical Digest, 2(2), 90-101.

Rodi, W. (2017). Turbulence models and their application in hydraulics. Routledge.

Rui, Z., Han, G., Zhang, H., Wang, S., Pu, H., \& Ling, K. (2017). A new model to evaluate two leak points in a gas pipeline. Journal of Natural Gas Science and Engineering, 46, 491-497.

Rui, Z., Lu, J., Zhang, Z., Guo, R., Ling, K., Zhang, R., \& Patil, S. (2017). A quantitative oil and gas reservoir evaluation system for development. Journal of Natural Gas Science and Engineering, 42, 31-39.

Rui, Z., Li, C., Peng, F., Ling, K., Chen, G., Zhou, X., \& Chang, H. (2017). Development of Industry performance metrics for offshore oil and gas project. Journal of Natural Gas Science and Engineering, 39, 44-53. 
Rui, Z., Peng, F., Chang, H., Ling, K., Chen, G., and Zhou, X., 2017, Investigation into the performance of oil and gas projects, Journal of Natural Gas Science and Engineering, 38, $12-20$.

Scott, S. L., \& Satterwhite, L. A. (1998). Evaluation of the backpressure technique for blockage detection in gas flowlines. Journal of energy resources technology, 120(1), 2731.

Scott, S. L., \& Yi, J. (1999). Flow testing methods to detect and characterize partial blockages in looped subsea flowlines. Journal of energy resources technology, 121(3), 154-160.

Vitkovsky, J. P., Lee, P. J., Stephens, M. L., Lambert, M. F., Simpson, A. R., \& Liggett, J. A. (2003). Leak and blockage detection in pipelines via an impulse response method. Pumps, electromechanical devices and systems applied to urban water management, 1, 423-430.

Yadav, A. S., \& Bhagoria, J. L. (2013). A CFD (computational fluid dynamics) based heat transfer and fluid flow analysis of a solar air heater provided with circular transverse wire rib roughness on the absorber plate. Energy, 55, 1127-1142.

Wagner, H. N., McAFEE, J. G., \& MOZLEY, J. M. (1961). Diagnosis of pericardial effusion by radioisotope scanning. Archives of internal medicine, 108(5), 679-684.

Wang, X., Lennox, B., Turner, J., Lewis, K., Ding, Z., Short, G., \& Dawson, K. (2009). Blockage detection in long lengths of pipeline using a new acoustic method. In Proceeding 
of 16th international congress on sound and vibration, ICSV16. Kraków, Poland (Vol. 1, pp. 140-147).

Watanabe, K., \& Himmelblau, D. M. (1986). Detection and location of a leak in a gastransport pipeline by a new acoustic method. AIChE Journal, 32(10), 1690-1701.

Watanabe, K., \& Himmelblau, D. M. (1986). Detection and location of a leak in a gastransport pipeline by a new acoustic method. AIChE Journal, 32(10), 1690-1701. 